\title{
AMPK is essential for energy homeostasis regulation and glucose sensing by POMC and AgRP neurons
}

Marc Claret,, ${ }^{1}$ Mark A. Smith, ${ }^{2}$ Rachel L. Batterham, ${ }^{1}$ Colin Selman, ${ }^{1}$ Agharul I. Choudhury, ${ }^{1}$ Lee G.D. Fryer, ${ }^{3}$ Melanie Clements, ${ }^{1}$ Hind Al-Qassab, ${ }^{1}$ Helen Heffron, ${ }^{1}$ Allison W. Xu, ${ }^{4}$ John R. Speakman, ${ }^{5}$ Gregory S. Barsh, ${ }^{4}$ Benoit Viollet, ${ }^{6}$ Sophie Vaulont, ${ }^{6}$ Michael L.J. Ashford, ${ }^{2}$ David Carling, ${ }^{3}$ and Dominic J. Withers ${ }^{1}$

\begin{abstract}
${ }^{1}$ Centre for Diabetes and Endocrinology, Rayne Institute, University College London, London, United Kingdom. ${ }^{2}$ Neurosciences Institute, Pathology and Neuroscience Division, Ninewells Hospital and Medical School, University of Dundee, Dundee, United Kingdom. ${ }^{3}$ Cellular Stress Group, MRC Clinical Sciences Centre, Imperial College London, London, United Kingdom. ${ }^{4}$ Department of Genetics and Department of Pediatrics, Stanford University School of Medicine, Stanford, California, USA. ${ }^{5}$ Aberdeen Centre for Energy Regulation and Obesity, University of Aberdeen, Aberdeen, United Kingdom.
\end{abstract} 6INSERM U567, CNRS, UMR 8104, Institut Cochin, Université René Descartes, Paris, France.

\begin{abstract}
Hypothalamic AMP-activated protein kinase (AMPK) has been suggested to act as a key sensing mechanism, responding to hormones and nutrients in the regulation of energy homeostasis. However, the precise neuronal populations and cellular mechanisms involved are unclear. The effects of long-term manipulation of hypothalamic AMPK on energy balance are also unknown. To directly address such issues, we generated POMC $\alpha 2 K O$ and $A g R P \propto 2 K O$ mice lacking $A M P K \alpha 2$ in proopiomelanocortin- (POMC-) and agouti-related protein-expressing (AgRP-expressing) neurons, key regulators of energy homeostasis. POMC $2 \mathrm{KO}$ mice developed obesity due to reduced energy expenditure and dysregulated food intake but remained sensitive to leptin. In contrast, $A g R P \propto 2 K O$ mice developed an age-dependent lean phenotype with increased sensitivity to a melanocortin agonist. Electrophysiological studies in $A M P K \alpha 2$-deficient POMC or AgRP neurons revealed normal leptin or insulin action but absent responses to alterations in extracellular glucose levels, showing that glucose-sensing signaling mechanisms in these neurons are distinct from those pathways utilized by leptin or insulin. Taken together with the divergent phenotypes of $P O M C \alpha 2 K O$ and $A g R P \alpha 2 K O$ mice, our findings suggest that while AMPK plays a key role in hypothalamic function, it does not act as a general sensor and integrator of energy homeostasis in the mediobasal hypothalamus.
\end{abstract}

\section{Introduction}

The AMP-activated protein kinase (AMPK) is an evolutionarily conserved sensor of cellular energy status $(1,2)$. AMPK is a heterotrimeric protein with an $\alpha$ catalytic subunit and $\beta$ and $\gamma$ regulatory subunits with multiple subunit isoforms $(2 \alpha, 2 \beta$, and $3 \gamma)$ existing in mammals (1). AMPK is allosterically activated by intracellular AMP levels, which increase under conditions of cellular stress or energy deficiency, such as hypoxia, ischemia, and glucose deprivation $(1,2)$. AMPK is also activated by phosphorylation of a conserved threonine in the activation loop (Thr172) by upstream kinases, which include the Peutz-Jegher syndrome tumor-suppressor gene product LKB1 and $\mathrm{Ca}^{2+} /$ calmodulin-dependent protein kinase kinase- $\beta$ (CaMKK $\beta$ ) (3-7). In general, AMPK activates catabolic pathways that generate ATP and switches off ATP-con-

Nonstandard abbreviations used: AgRP, agouti-related protein; $A g R P \alpha 2 K O$ mice, mice lacking AMPK 2 in AgRP neurons; AMPK, AMP-activated protein kinase; ARC, arcuate nucleus; $\mathrm{CamKK}, \mathrm{Ca}^{2+} /$ calmodulin-dependent protein kinase kinase; $\mathrm{DEE}$, daily energy expenditure; DEXA, dual-energy $\mathrm{x}$-ray absorptiometry; $\alpha 1 \mathrm{HetPOMC \alpha 2KO}$ mice, mice heterozygous-null for $A M P K \alpha 1$ and lacking $A M P K \alpha 2$ in POMC neurons; $\mathrm{HFD}$, high-fat diet; $\mathrm{K}_{\mathrm{ATP}}$ channel, ATP-sensitive potassium channel; $\alpha 1$ KOPOMCO2KO mice, mice null for $A M P K \alpha 1$ and lacking $A M P K \alpha 2$ in POMC neurons; MC3/4R, melanocortin $3 / 4$ receptor; $\alpha$-MSH, $\alpha$-melanocyte-stimulating hormone; MT-II, melanotan II; NPY, neuropeptide Y; POMC, proopiomelanocortin; POMC 2 KO mice, mice lacking $A M P K \alpha 2$ in POMC neurons; RMR, resting metabolic rate; $\mathrm{T} 4$, thyroxine; $\mathrm{Vm}$, membrane potential; YFP, yellow fluorescent protein.

Conflict of interest: The authors have declared that no conflict of interest exists. Citation for this article: J. Clin. Invest. 117:2325-2336 (2007). doi:10.1172/JCI31516 suming processes through acute phosphorylation of metabolic enzymes and long-term alterations in gene expression (1).

While it was originally considered primarily as a gauge of cellular energy status, accumulating evidence indicates that AMPK regulates whole-body energy homeostasis, acting in metabolic tissues in response to nutrient and hormonal signals $(1,2)$. In skeletal muscle, the adipokines leptin and adiponectin, as well as exercise, activate AMPK, thus stimulating fatty acid oxidation (8, 9). In liver, AMPKa2 is a key target for the suppression of hepatic glucose production by leptin and adiponectin, and in adipose tissue AMPK signaling antagonizes lipolysis $(10,11)$. Therefore, in peripheral tissues, AMPK signaling regulates substrate oxidation and fuel storage, with the overall effect of maintaining the appropriate partitioning of metabolites.

More recently, it has been suggested that AMPK acts as a general energy sensor and integrator of nutrient and hormonal signals in the CNS $(1,12)$. Hypothalamic AMPK $\alpha 2$ activity is reduced by high glucose levels, the physiological transition from the fasted to the fed state, and by the anorexigenic hormones leptin and insulin (13-15). In contrast, the orexigenic hormone ghrelin stimulates hypothalamic AMPK $\alpha 2$ activity $(14,16)$. Activation of AMPK by 5-amino-4-imidazolecarboxamide riboside (AICAR) or adenoviral expression of activated AMPK mutants in the mediobasal hypothalamus have been reported to stimulate food intake, while dominant-negative AMPK mutants reduce food intake (13-15). In vitro studies using transformed hypothalamic cell lines support such 
A

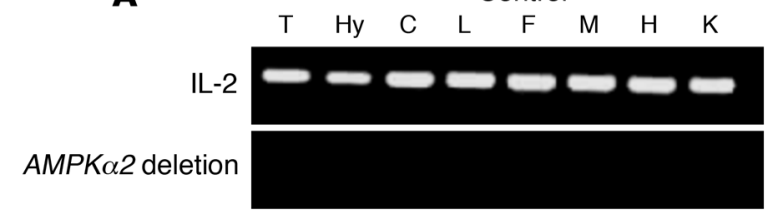

B

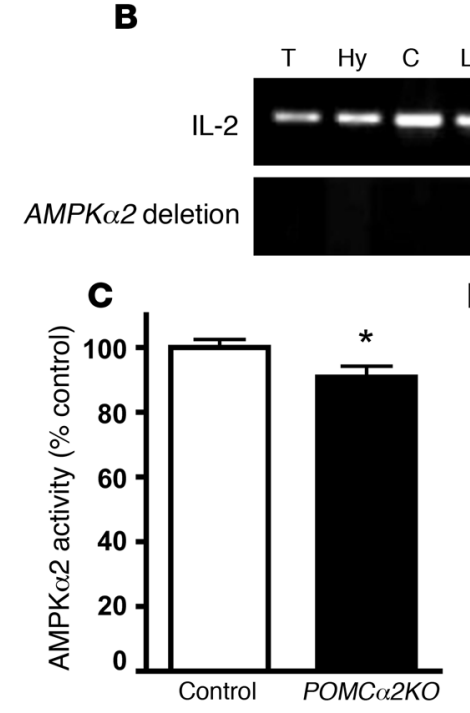

Control
D

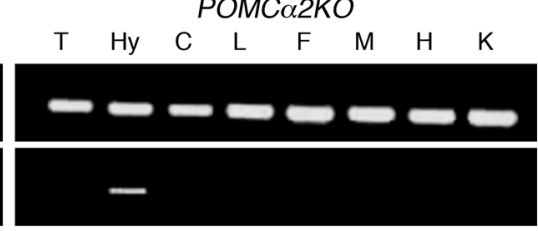

AgRP $\alpha 2 K O$
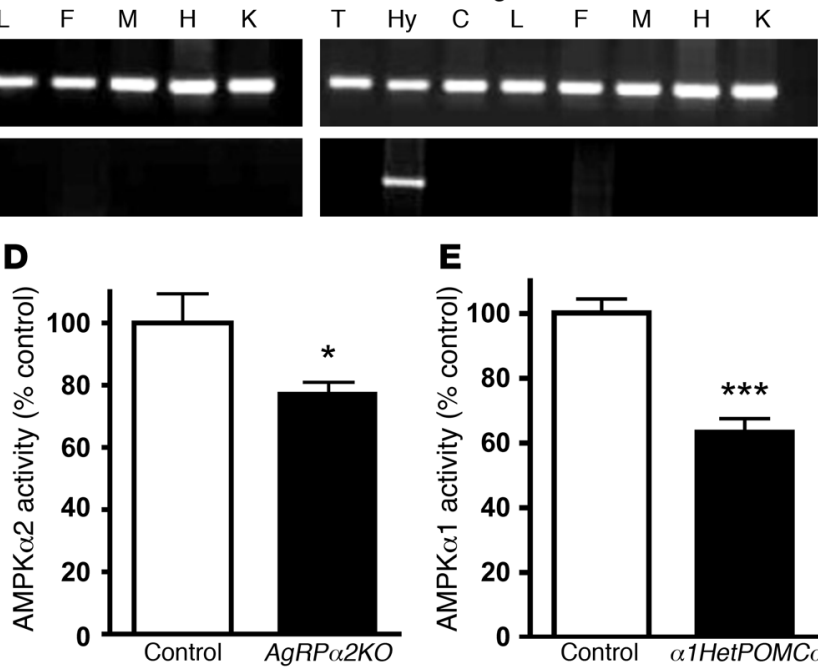

E

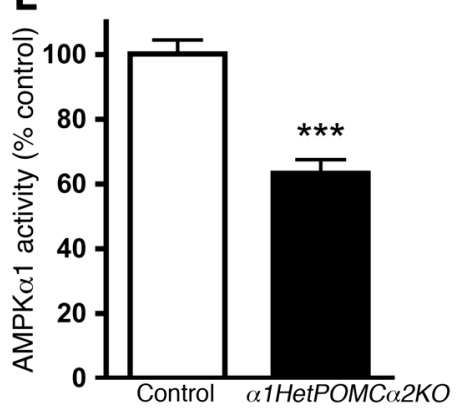

Figure 1

Reduction in hypothalamic AMPK $\alpha 2$ activity in POMC $\alpha 2 K O$ and $A g R P \alpha 2 K O$ mice. Detection of deletion of $A M P K \alpha 2$ allele in $P O M C \alpha 2 K O(\mathbf{A})$ and $A g R P \alpha 2 K O$ mice (B). DNA was extracted from different tissues ( $\mathrm{T}$, tail; Hy, hypothalamus; C, cerebral cortex; L, liver; F, fat; M, skeletal muscle; H, heart; K, kidney) and recombination of the floxed $A M P K \alpha 2$ allele detected by PCR. Recombination was only detected in the hypothalamus of $P O M C \alpha 2 K O(\mathbf{A})$ and $A g R P \alpha 2 K O$ mice (B). A PCR reaction with IL-2 as internal control is also shown. AMPK $\alpha 2$ activity in hypothalamic lysates from $P O M C \alpha 2 K O(\mathbf{C} ; n=11-13)$ and $A g R P \alpha 2 K O$ mice (D; $n=7)$. (E) AMPK $\alpha 1$ kinase activity in hypothalamic lysates from $\alpha 1$ HetPOMC $\alpha 2 K O$ mice $(n=11-12)$. All values are mean \pm SEM. ${ }^{*} P<0.05 ;{ }^{* \star *} P<0.001$.

results (17). The proposed model resulting from these observations suggests that anorexigenic signals inhibit AMPK activity directly in arcuate nucleus (ARC) orexigenic agouti-related protein/neuropeptide $\mathrm{Y}(\mathrm{AgRP} / \mathrm{NPY})$ neurons (13). Furthermore, leptin is suggested to indirectly regulate hypothalamic paraventricular nucleus AMPK activity via $\alpha$-melanocyte-stimulating hormone $(\alpha-\mathrm{MSH})$ release and action at melanocortin 3/4 receptors (MC3/4Rs) (13).

While implicating AMPK in the regulation of food intake, these studies have not given insights into the function of AMPK in specific hypothalamic neuronal populations. Furthermore, use of transient adenoviral expression systems has in general not permitted the study of the long-term effects of manipulating AMPK in the hypothalamus on body weight or energy expenditure. The potential effects of manipulating AMPK signaling in specific hypothalamic neurons on their electrophysiological responses to hormones and nutrients are also unclear. Therefore, to define the role of AMPK in the hypothalamus, we generated mice deficient in $A M P K \alpha 2$ (with or without combined global $A M P K \alpha 1$ deletion) specifically in Pomc- or Agrp-expressing neurons, major components of the pathways regulating food intake and energy expenditure (18-20). Mice lacking AMPK 22 in POMC neurons developed obesity due to reduced metabolic rate and dysregulated feeding but remain sensitive to leptin. In contrast, mice lacking $A M P K \alpha 2$ in AgRP neurons displayed an age-dependent lean phenotype POMC or AgRP neurons $(20,23)$ to generate a series of mutant strains: POMC $22 K O$ mice (lacking AMPK 2 in POMC neurons), $\alpha 1 \mathrm{HetPOMC} \alpha 2 \mathrm{KO}$ mice (lacking AMPK $\alpha 2$ in POMC neurons and heterozygous-null for $A M P K \alpha 1$ in all tissues), $\alpha 1$ KOPOMC $\alpha 2 K O$ mice (lacking $A M P K \alpha 2$ in POMC neurons and $A M P K \alpha 1$ null in all tissues), and $A g R P \alpha 2 K O$ mice (lacking $A M P K \alpha 2$ in AgRP neurons). Deletion of $A M P K \alpha 2$ was restricted to the hypothalamus in POMC and AgRP mutants, as determined by PCR analysis of the recombination event (Figure 1, A and B). To demonstrate that this deletion was accompanied by a reduction in hypothalamic AMPKo2 activity, we performed immune complex kinase assays in mediobasal hypothalamic lysates from 4- to 6-week-old $P O M C \alpha 2 K O$ and $A g R P \alpha 2 K O$ mice. Both POMC $22 K O$ and AgRP $2 K O$ mutants had a small but significant reduction in hypothalamic AMPKo2 activity (Figure 1, C and D), whereas a1HetPOMCa2KO mice had an approximately $50 \%$ reduction in hypothalamic AMPK $\alpha 1$ activity, indicating that haploinsufficiency leads to a reduction in AMPK $\alpha 1$ expression (Figure 1E). In contrast, there was no difference in AMPK $\alpha 2$ activity in a range of peripheral tissues between control and hypothalamic mutant mice (data not shown). To further determine the extent of deletion, we performed immunostaining for AMPK 22 in POMC and AgRP neurons from POMC $2 \mathrm{KO}$ mice and $A g R P \alpha 2 K O$ mice, respectively. These studies revealed deletion of AMPKa2 expression in approximately $90 \%$ of the 2 neuronal 

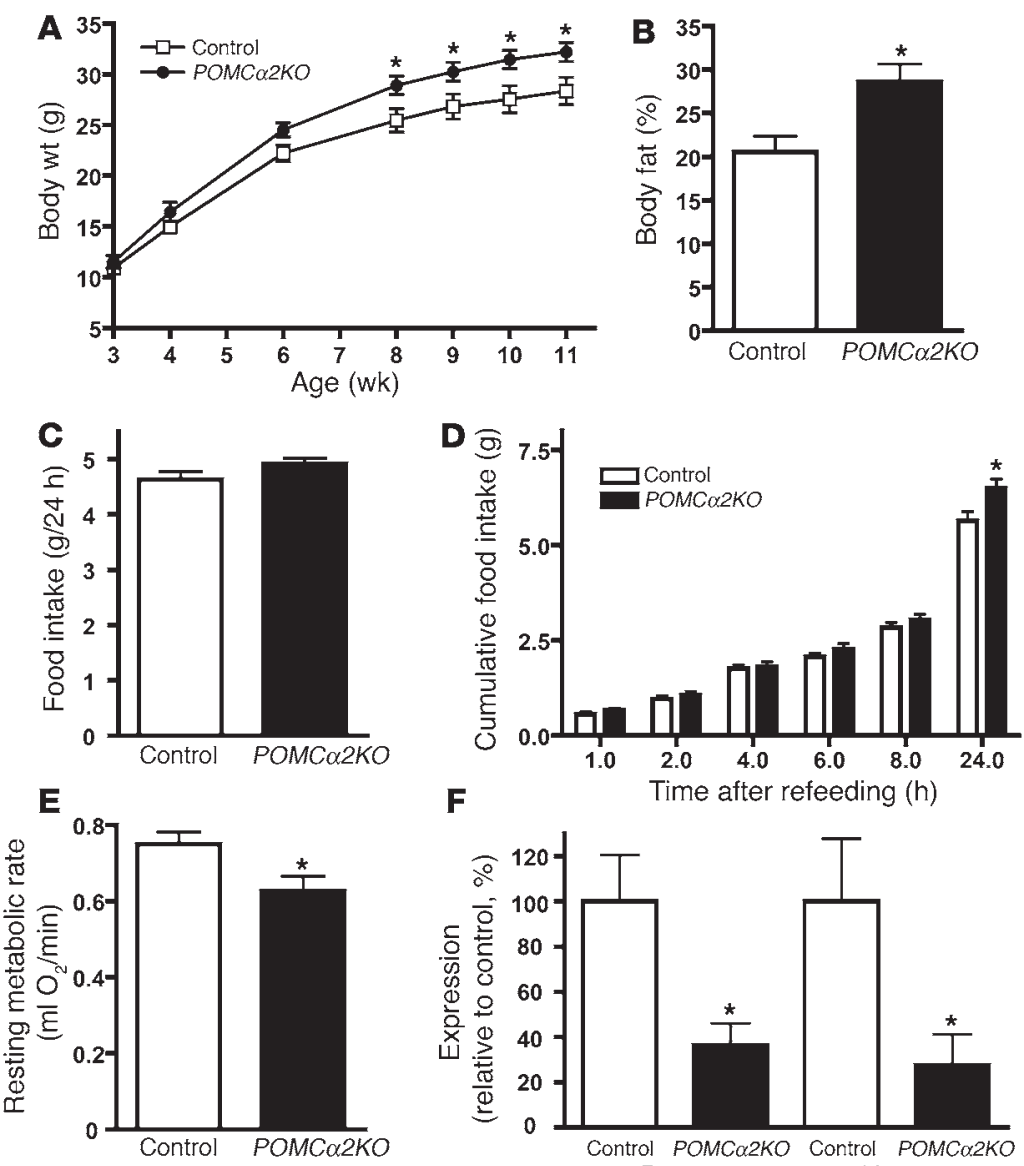

$\mathbf{F}$
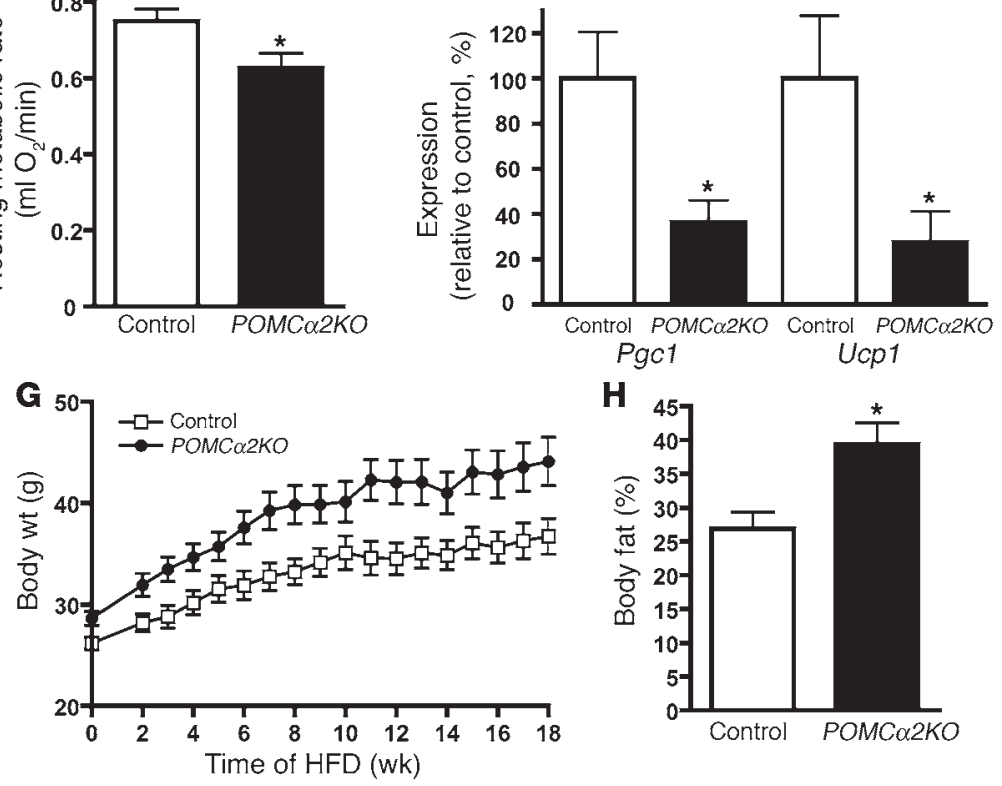

\section{Figure 2}

Mice lacking $A M P K \alpha 2$ in POMC neurons are obese and have increased food intake and reduced energy expenditure. (A) Weight curves of male control and $P O M C \alpha 2 K O$ mice on a chow diet; $n=8$. (B) Percentage body fat determined by DEXA scanning in 19-week-old male control and POMC $\alpha 2 K O$ mice; $n=6$. (C) Twentyfour-hour food intake under ad libitum feeding conditions in 12-week-old male control and POMC $22 K O$ mice; $n=8$. (D) Cumulative 24-hour food intake in 12-weekold male control and POMC $\alpha 2 K O$ mice in response to an overnight fast; $n=8$. (E) RMR determined by open-flow respirometry in 18-week-old control and POMC $\alpha 2 K O$ mice; $n=11$ and $n=8$, respectively. (F) PPAR $\gamma$ coactivator-1 (Pgc1) and uncoupling-protein 1 (Ucp1) mRNA levels in brown adipose tissue (BAT) assessed by quantitative RT-PCR; $n=5-7$. Probes for GAPDH were used to adjust for total RNA content. (G) Weight curves of male control and POMC $\alpha 2 K O$ mice on exposure to HFD; $n=11-15$. $P<0.05$ at all time points, except weeks 7 and 9, where $P<0.01$. (H) Percentage body fat determined by DEXA scanning in male control and POMC $\alpha 2 K O$ mice after 18 weeks on a HFD; $n=5$. All values are mean \pm SEM. ${ }^{*} P<0.05$.

normal organ weights relative to body weight when compared with control mice (data not shown). Daily food intake was not altered under ad libitum conditions, but following an overnight fast, compensatory feeding was significantly increased in POMC $2 \mathrm{KO}$ mice (Figure 2, C and D). Open-flow respirometry studies demonstrated that POMC 2 KO mice had a significantly reduced resting metabolic rate (RMR) (Figure 2E). Daily energy expenditure (DEE; kJ/d) was calculated using the doubly labeled water technique (24). RMR was converted to kilojoules per day to determine whether the physical activity and thermoregulatory components of DEE (DEE minus RMR) were altered (25). No difference in DEE (-RMR) was seen in POMCa2KO mice (control: $51.3 \pm 2.6 \mathrm{~kJ} / \mathrm{d}$ versus $P O M C \alpha 2 K O: 55.9 \pm 2.1 \mathrm{~kJ} / \mathrm{d} ; n=11$ and $n=8$, respectively; NS), demonstrating that only RMR was decreased. Consistent with reduced RMR, mRNA levels of PPAR $\gamma$ coactivator-1 $\alpha($ Pgc1a) and uncoupling-protein 1 (Ucp1) were significantly decreased in brown adipose tissue (BAT) from POMC $2 \mathrm{KO}$ mice

populations (Supplemental Figure 1, A-C; supplemental material available online with this article; doi:10.1172/JCI31516DS1). Together, these results demonstrate appropriate and cell-specific reductions in hypothalamic AMPK $\alpha 2$ expression and activity in both POMC $22 K O$ and $A g R P \alpha 2 K O$ mutants and suggest that there is no compensatory upregulation in other hypothalamic regions. Thus, these mice permitted a detailed examination of the impact of reduced AMPK $\alpha 2$ signaling in specific hypothalamic neurons upon whole-body energy homeostasis.

POMCa2KO mice have increased body weight and adiposity. $P O M C \alpha 2 K O$ mice developed an age-dependent increase in body weight that was significant by 8 weeks of age (Figure 2A). By 11 weeks of age, male POMC $2 \mathrm{KO}$ mice weighed approximately $15 \%$ more than littermate controls (Figure 2A). Dual-energy x-ray absorptiometry (DEXA) scanning revealed significantly increased total body fat in POMCa2KO mice (Figure 2B). Mutant mice had
(Figure 2F). Moreover, exposure of POMC $2 \mathrm{KO}$ mice to a high-fat diet (HFD) for 18 weeks potentiated the obesity phenotype and adiposity in these animals, further demonstrating a defect in the appropriate handling of nutrients (Figure 2, G and $\mathrm{H}$ ).

The obesity phenotype in POMC $2 \mathrm{KO}$ mice is not due to anatomical or functional disruption of POMC neurons or compensatory upregulation of $A M P K \alpha 1$. Leptin and other anorexigenic signals have been reported to suppress AMPK $\alpha 2$ activity in hypothalamic lysates (13-15). It was therefore anticipated that $A M P K \alpha 2$ deletion and the resulting reduction in hypothalamic AMPK $\alpha 2$ activity seen in $P O M C \alpha 2 K O$ mice would inhibit food intake and reduce body weight. Potential explanations for the opposite phenotype in POMCa2KO mice include disruption of POMC neuronal anatomy and function, such as altered $\alpha$-MSH release or compensatory upregulation of AMPK $\alpha 1$ in POMC neurons, and therefore we undertook studies to address these issues. 
A

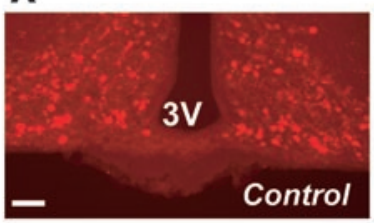

D

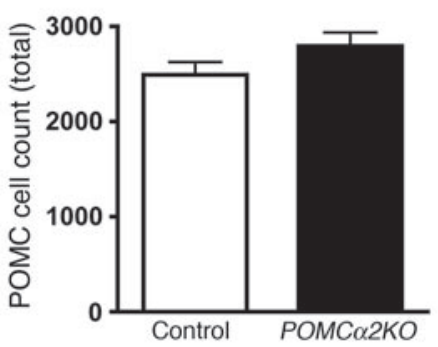

F
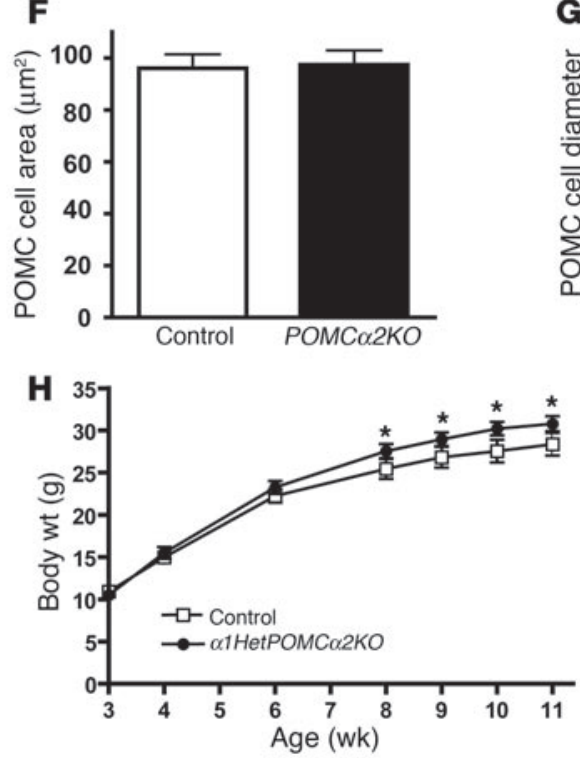

B

E
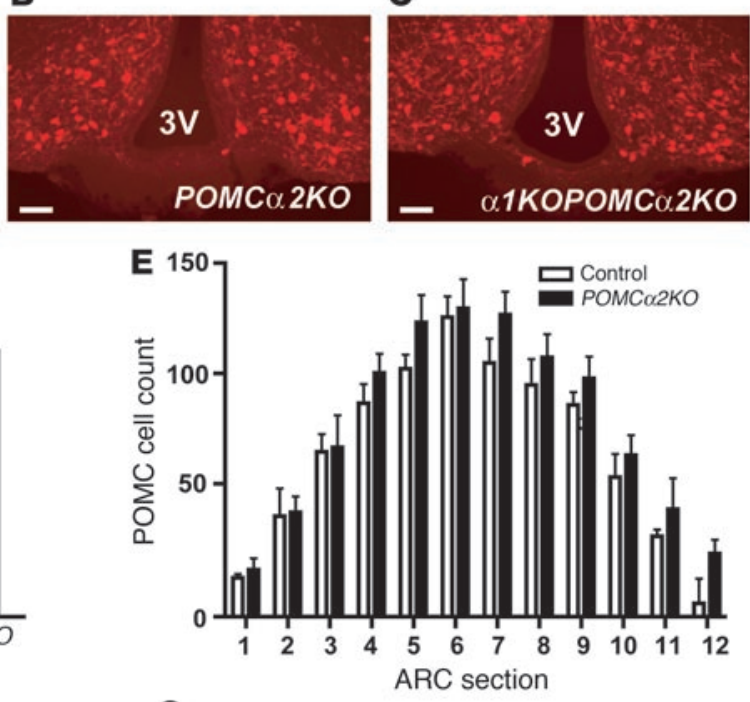

G
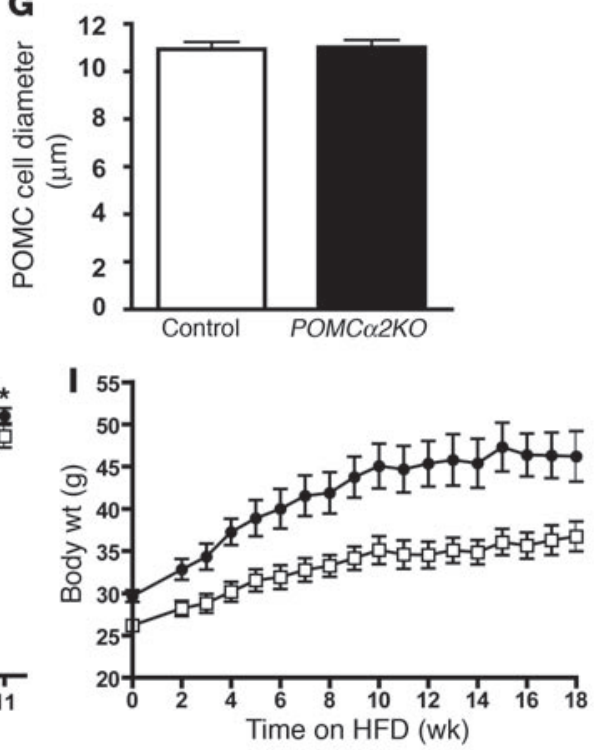

\section{Figure 3}

Obesity phenotype in POMC $\alpha 2 K O$ mice is not due to anatomical or functional disruption of POMC neurons or compensatory upregulation of AMPK $\alpha 1$. Immunoreactivity for $\alpha-\mathrm{MSH}$ in ARC of control $(\mathbf{A})$, $P O M C \alpha 2 K O(B)$, and $\alpha 1 K O P O M C \alpha 2 K O$ (C) mice. Representative sections from 4 mice for each genotype are presented. Population size and distribution ( $D$ and E) for POMC neurons within the ARC in control and POMC $\alpha 2 K O$ mice $(n=4-6)$. POMC somatic area $(\mathbf{F})$ and diameter $(\mathbf{G})$ in control and POMC $\alpha 2 K O$ mice $(n=4-6)$. A minimum of 500 neurons were analyzed per group. 3V, third ventricle. Scale bars: 50 $\mu \mathrm{m}$. (H) Weight curves of male control and a1HetPOMC $\alpha 2 K O$ mice on a chow diet; $n=8$. (I) Weight curves of male control and $\alpha 1 \mathrm{HetPOMC} \alpha 2 \mathrm{KO}$ mice on exposure to HFD; $n=10 . P<0.05$ at all time points, except weeks $0,2,7,8,11,12,13,14$, and 15 , where $P<0.01$. All values are mean \pm SEM. ${ }^{*} P<0.05$.
Anatomical analysis of POMC neurons in 3-month-old $P O M C \alpha 2 K O$ mice revealed no alterations in location, population size, or somatic dimensions when compared with those in control animals (Figure 3, A-G). Indeed, POMC neurons appeared normal in mice lacking both $A M P K \alpha 1$ and $A M P K \alpha 2$ in this cell type (Figure $3 \mathrm{C}$ ). Electrophysiological studies showed that the biophysical properties of ARC POMC neurons were statistically indistinguishable between control and AMPK 2 2-deleted mice (Table 1). Ex vivo hypothalamic slice studies showed that $\alpha$-MSH release from POMC $22 \mathrm{KO}$ slices was equivalent to that seen in control slices (Supplemental Figure 2A). These data demonstrate that chronic $A M P K \alpha 2$ deletion does not alter POMC neuronal distribution, number, morphology, basic electrical properties, or $\alpha-\mathrm{MSH}$ release from this cell type.

Hypothalamic AMPK $\alpha 1$ activity has not been reported to be regulated by hormones or nutrients, and AMPK 1 -globalnull mice have a normal metabolic phenotype $(13,22)$. However, mice with global deletion of $A M P K \alpha 2$ are reported to show upregulation of AMPK $\alpha 1$ expression in some tissues (26). There- fore, we studied $\alpha 1 \mathrm{HetPOMC} \alpha 2 \mathrm{KO}$ and $\alpha 1$ KOPOMC $\alpha 2 \mathrm{KO}$ mice using a genetic approach to exclude the possibility that compensatory upregulation of $A M P K \alpha 1$ in POMC neurons lacking $A M P K \alpha 2$ caused the POMC $2 \mathrm{KO}$ mouse phenotype. Body weight profiles in $\alpha 1 \mathrm{HetPOMC} \alpha 2 \mathrm{KO}$ mice were similar to those seen in POMC $\alpha 2 \mathrm{KO}$ mice on a normal diet and more severe when animals were exposed to a HFD (Figure 3, H and I). $\alpha 1$ KOPOMC $\alpha 2 \mathrm{KO}$ mice on a normal diet also displayed increased body weight (8-week-old male, control: $25.7 \pm 0.3$ g versus $\alpha 1$ KOPOMC $\alpha 2 K O: 27.5 \pm 0.4 \mathrm{~g} ; n=6 ; P<0.05$ ). These findings exclude potential upregulation of $A M P K \alpha 1$ as a cause of the increased body weight phenotype in POMC $22 \mathrm{KO}$ mice.

$P O M C \alpha 2 K O$ mice have normal leptin sensitivity but altered neuropeptide expression. To further investigate the mechanisms underlying the hypothalamic phenotype in POMC $2 \mathrm{KO}$ mice, we examined the response of these animals to leptin and the MC3/4R agonist melanotan II (MT-II), both suggested to act in part via AMPK (13). Four-week-old POMC 2 KO mice had normal leptin levels (Figure $4 \mathrm{~A})$ suggesting that these animals do not have primary leptin resistance. By 12 weeks of age, POMC $22 \mathrm{KO}$ mice displayed hyperlep- 
Table 1

The biophysical properties of ARC POMC-expressing neurons in control and POMCa2KO mice

\begin{tabular}{lcc}
\hline & Control & POMC $\alpha$ 2KO \\
Membrane potential $(\mathrm{mV})$ & $-48 \pm 1(13)$ & $-46 \pm 1(20)$ \\
Input resistance $(\mathrm{G} \Omega)$ & $1.8 \pm 0.1(9)$ & $1.9 \pm 0.1(20)$ \\
Spike firing frequency $(\mathrm{Hz})$ & $2.7 \pm 0.4(13)$ & $3.3 \pm 0.6(20)$ \\
Membrane capacitance $(\mathrm{pF})$ & $8.5 \pm 1.0(12)$ & $8.3 \pm 0.5(12)$ \\
mIPSC amplitude $(\mathrm{pA})$ & $-46 \pm 4(6)$ & $-56 \pm 8(6)$ \\
mIPSC frequency (Hz) & $1.4 \pm 0.6(6)$ & $1.3 \pm 0.4(6)$ \\
mEPSC amplitude (pA) & $-13 \pm 1(6)$ & $-16 \pm 1(6)$ \\
mEPSC frequency (Hz) & $0.6 \pm 0.2(6)$ & $1.1 \pm 0.3(6)$ \\
\end{tabular}

Data are expressed as mean \pm SEM. The number of neurons per group is shown in parentheses. mIPSC, miniature inhibitory postsynaptic current; mEPSC, miniature excitatory postsynaptic current.

tinemia consistent with the development of obesity (Figure 4A). However, these animals were sensitive to the weight- and food intake-reducing effects of exogenously administered leptin (Figure 4, B and C). In addition, they displayed normal sensitivity to MT-II, which produced an equivalent reduction in food intake in $P O M C \alpha 2 K O$ and control mice (Figure 4, D and E).

Leptin has also been implicated in the central regulation of body length, bone mineral density, and glucose, insulin, corticosterone, and thyroxine (T4) levels (27-30). However, none of these parameters were altered in POMC 2 KO mice (Supplemental Table 1).
Expression of mRNA for pre-POMC, growth hormone, and thyroid-stimulating hormone were unaltered in the pituitaries of POMCa2KO mice (Supplemental Figure 2D). Plasma levels of adiponectin, which acts to regulate peripheral metabolism in part via AMPK (9), were also normal in POMC $22 \mathrm{KO}$ mice (Supplemental Table 1). Furthermore, glucose tolerance was not impaired in these animals except upon exposure to a HFD, after which mild glucose intolerance developed (Supplemental Figure 3, A and B). Insulin sensitivity was also normal in POMC 2 KO mice (data not shown).

We next measured hypothalamic neuropeptide expression by quantitative RT-PCR. While there was a trend toward lower levels of Pomc mRNA and higher levels of Agrp/Npy mRNA in POMC 2 KO mice, this did not reach statistical significance (data not shown). However, the ratio between orexigenic (Agrp, Npy) and anorexigenic (Pomc) mRNAs in the fasted state was significantly increased in POMCa2KO mice (Figure 4, F and G), suggesting imbalanced orexigenic and anorexigenic outputs in the hypothalamus. Taken together, these results demonstrate that AMPK activity in POMC neurons plays a role in the maintenance of energy homeostasis, but, contrary to the prevailing view, reduction in hypothalamic AMPK provides a mild orexigenic as opposed to an anorexigenic output.

Mice lacking AMPKa2 in AgRP neurons have reduced body weight. To further explore the role of AMPK signaling in hypothalamic function, we studied $A g R P \alpha 2 K O$ mice. In view of the lack of AMPK $\alpha 1$ compensation seen in $P O M C \alpha 2 K O$ mice, we restricted our analysis to mice lacking only $A M P K \alpha 2$ in AgRP neurons. Although complete deletion of floxed alleles does not occur in AgRP-Cre animals until 4 weeks of age $(20,23)$, we undertook studies to

\section{Figure 4}

$P O M C \alpha 2 K O$ mice are sensitive to leptin and a melanocortin agonist. (A) Fasting leptin levels in 4- and 12-week-old male control and POMC $\alpha 2 K O$ mice; $n=5-15$. (B) Body weight change in male control and $P O M C \alpha 2 K O$ mice on a chow diet after 3 consecutive days treatment with either vehicle or leptin $(2$ doses of $1.5 \mathrm{mg} / \mathrm{kg}$ body weight $/ \mathrm{d}) ; n=8$. (C) Cumulative food intake in male control and $P O M C \alpha 2 K O$ mice on a chow diet after 3 consecutive days treatment with either vehicle or leptin (2 doses of $1.5 \mathrm{mg} / \mathrm{kg}$ body weight/d); $n=8$. Cumulative food intake at the times indicated after injection of vehicle or MT-II following an overnight fast in 16-week-old male control (D) and $P O M C \alpha 2 K O$ mice (E); $n=8$. (F) Agrp/Pomc and (G) Npy/Pomc mRNA expression ratio in control and $P O M C \alpha 2 K O$ mice assessed by quantitative RT-PCR; $n=9-10$. Probes for hypoxanthine guanine phosphoribosyl transferase (HPRT) were used to adjust for total RNA content. All values are mean \pm SEM. ${ }^{\star} P<0.05 ;{ }^{\star \star \star} P<0.001$.
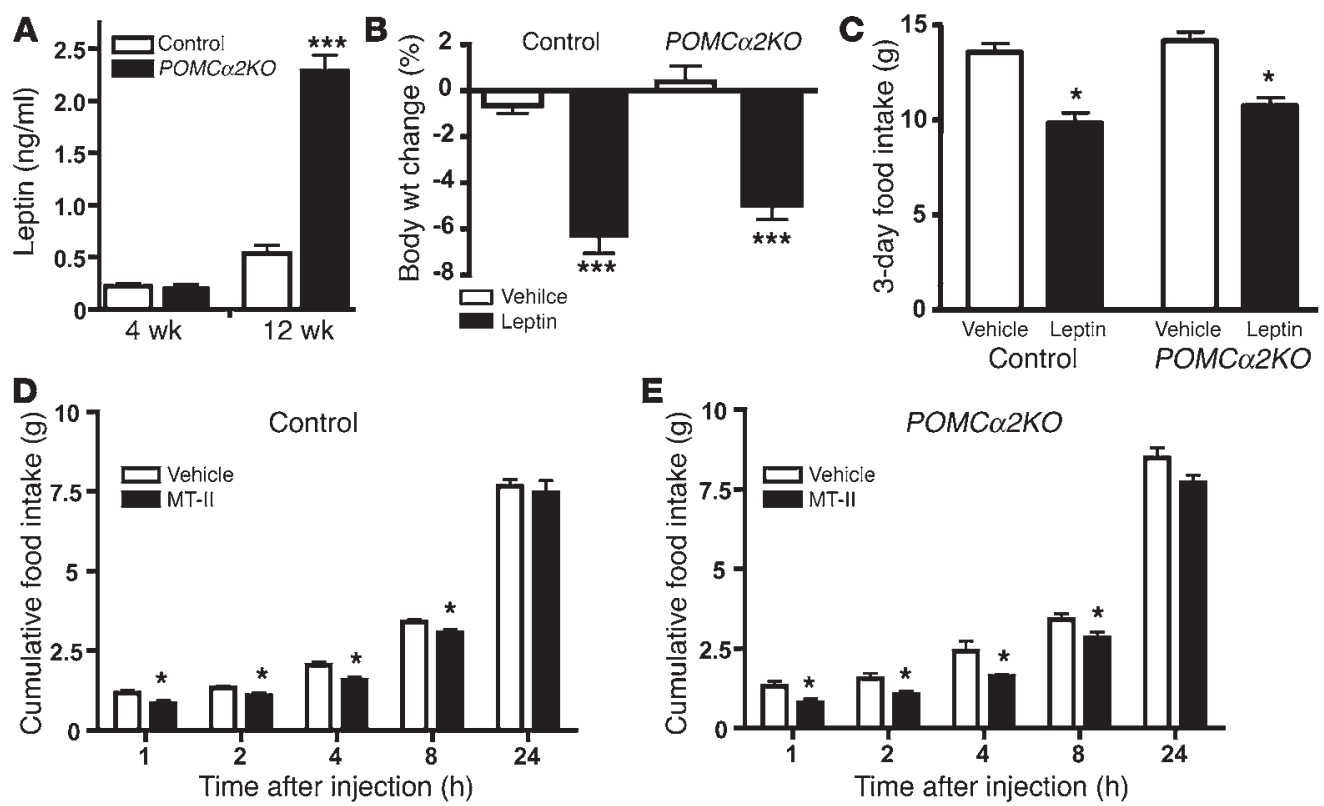

E
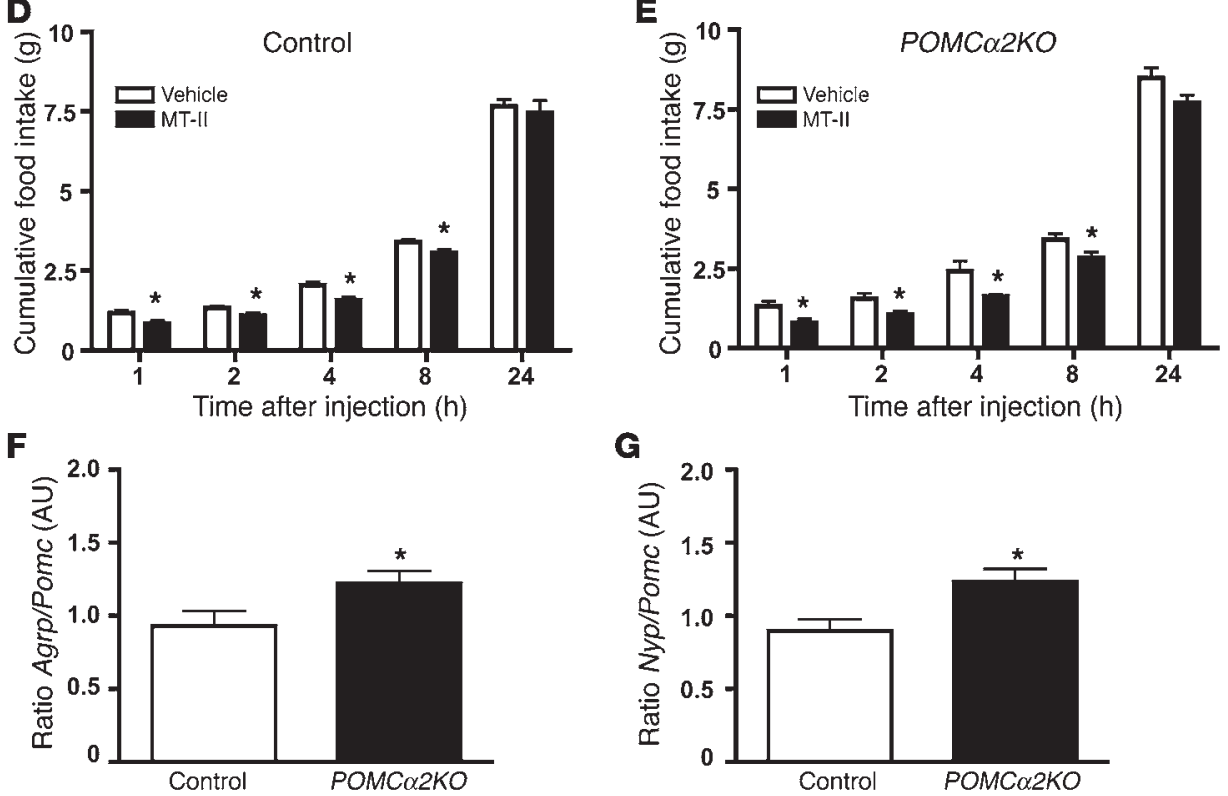

G

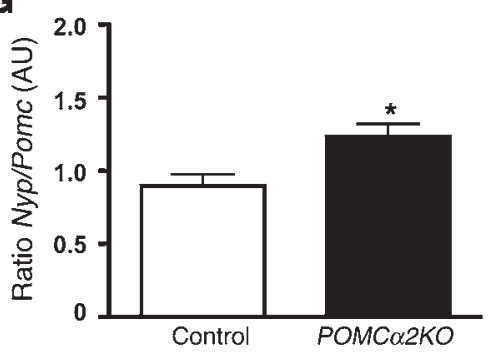



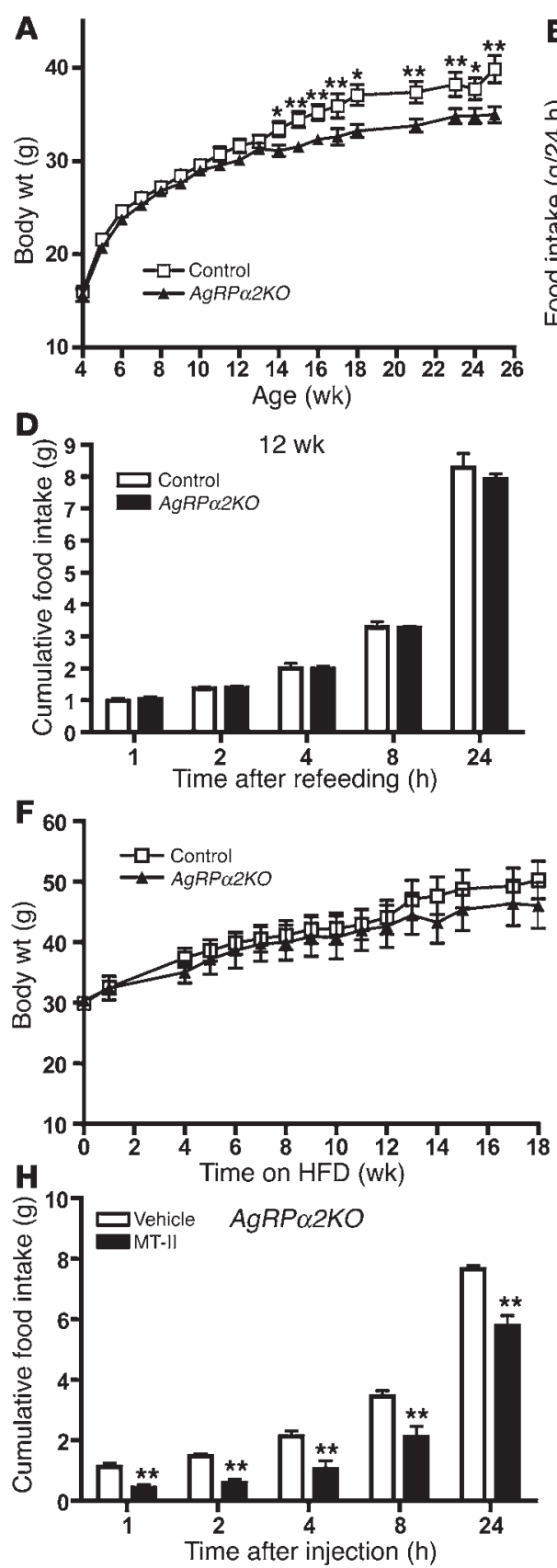

B

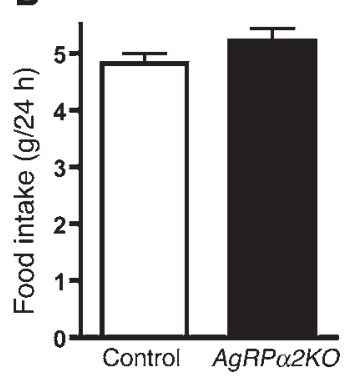

12 wk

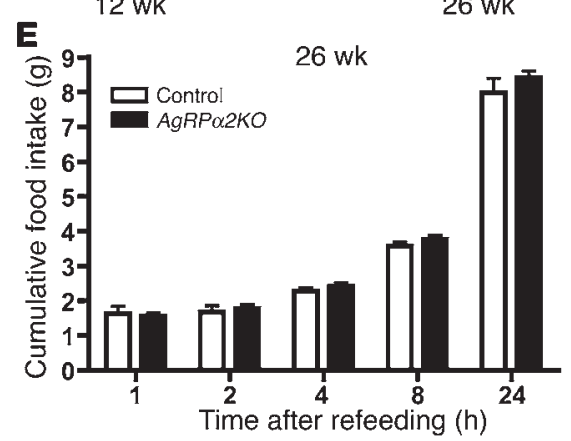

G

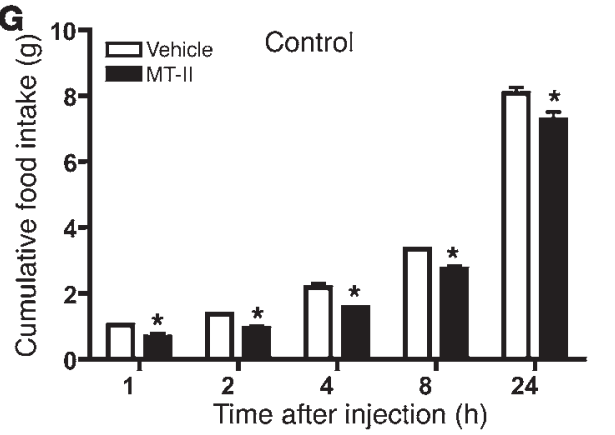

I

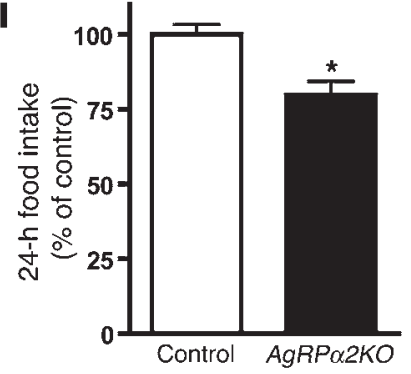

Figure 5

Mice lacking AMPKa2 in AgRP neurons display an age-dependent lean phenotype and have increased sensitivity to a melanocortin agonist. (A) Weight curves of male control and $A g R P \alpha 2 K O$ mice on a chow diet; $n=40$. (B and C) Twenty-four-hour food intake under ad libitum feeding conditions in 12- and 26-week-old male control and $A g R P a 2 K O$ mice on a chow diet; $n=8$. (D and E) Cumulative 24-hour food intake in 12- and 26-week-old male control and $A g R P \alpha 2 K O$ mice in response to an overnight fast; $n=8$. (F) Weight curves of male control and $A g R P \alpha 2 K O$ mice on exposure to HFD; $n=8$. Cumulative food intake at the times indicated after injection of vehicle or MT-II following an overnight fast in 16-week-old male control (G) and AgRP $\alpha 2 K O$ mice (H); $n=6$. (I) Percentage reduction in 24-hour food intake after injection of MT-II following an overnight fast in 16-week-old male control and $A g R P \alpha 2 K O$ mice; $n=6$. All values are mean \pm SEM. ${ }^{*} P<0.05 ;{ }^{* *} P<0.01$. exclude developmental disruption of the basic functions of this cell type. These studies revealed that there were no differences in the basic anatomy, AgRP and NPY release, and biophysical properties between AgRP and AgRP $22 \mathrm{KO}$ neurons, although the latter were slightly more hyperpolarized (Supplemental Figure 2, B and C, Supplemental Figure 4, A-F, and Supplemental Table 2). In contrast to POMC $2 \mathrm{KO}$ mice, $A g R P \alpha 2 K O$ mice displayed a mild but significant age-related reduction in body weight (Figure 5A). Similar to what has been reported for $A g R P$ global-null mice, the onset of this reduced body weight was seen after 3 months of age (31). To assess the underlying mechanisms for this subtle phenotype, we examined feeding behavior at 2 ages. At both 12 and 26 weeks of age, we detected no differences in food intake, either under ad libitum feeding conditions or in response to an overnight fast (Fig- ure 5, B-E). RMR was unchanged between control and $A g R P \alpha 2 K O$ mice (control: $0.77 \pm 0.03 \mathrm{ml} \mathrm{O}_{2} /$ min versus $A g R P \alpha 2 K O: 0.65 \pm 0.05$ $\mathrm{ml} \mathrm{O}_{2} / \mathrm{min} ; n=11$ and $n=8$, respectively; NS). DEE consisting only of the physical activity and thermoregulatory components (DEE minus RMR) was not altered in $A g R P \alpha 2 K O$ mice (control: $51.3 \pm 2.6 \mathrm{~kJ} / \mathrm{d}$ versus $A g R P \alpha 2 K O: 58.4 \pm 4.1 \mathrm{~kJ} / \mathrm{d} ; n=11$ and $n=8$, respectively; NS). When challenged with a HFD, $A g R P \alpha 2 K O$ mice had a non-statistically significant tendency to be lighter than control mice (Figure 5F). Leptin levels in AgRP $\alpha 2 K O$ mice were not different from those in control animals (control: $0.24 \pm 0.05$ $\mathrm{ng} / \mathrm{ml}$ versus $A g R P \alpha 2 K O: 0.26 \pm 0.02 \mathrm{ng} / \mathrm{ml} ; n=9 ; \mathrm{NS}$ ). Moreover, there were no differences in hypothalamic neuropeptide expression or Agrp/Pomc and Npy/Pomc mRNA ratios between control and $A g R P \alpha 2 K O$ mice (data not shown). Plasma levels of glucose, 
A
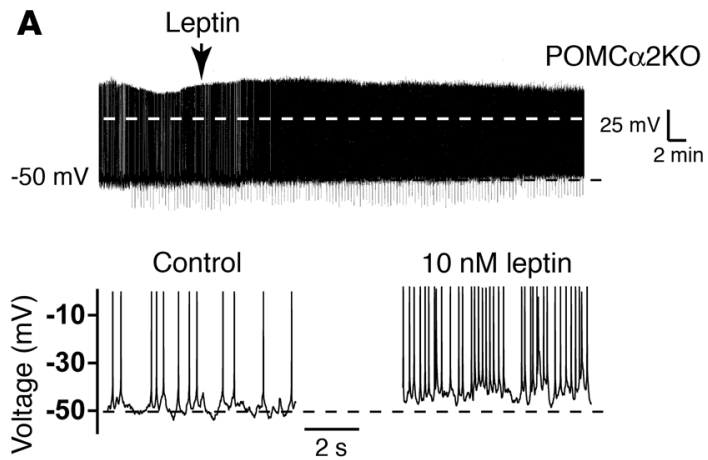

C $\quad 0.1 \mathrm{mM}$ glucose

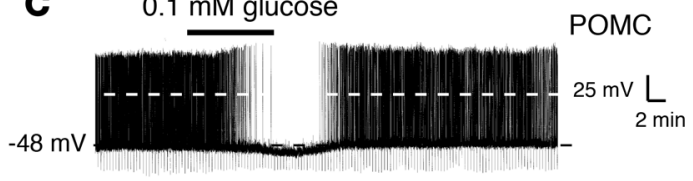

$2 \mathrm{mM}$ glucose $\quad 0.1 \mathrm{mM}$ glucose

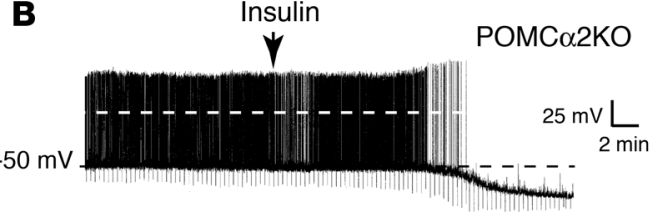

Control

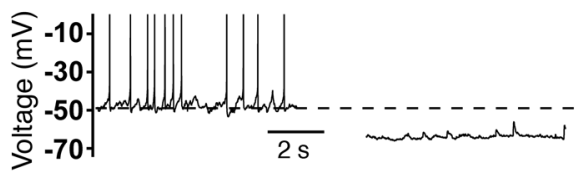

D

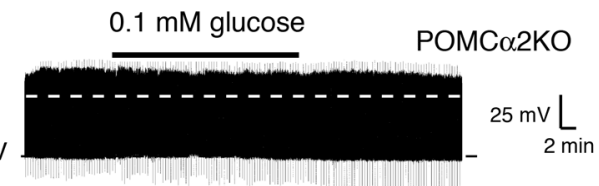

$2 \mathrm{mM}$ glucose $\quad 0.1 \mathrm{mM}$ glucose

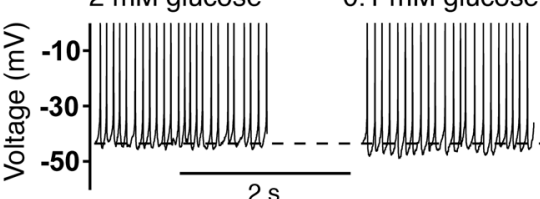

\section{Figure 6}

POMC neurons lacking $A M P K \alpha 2$ respond to anorexigenic hormones but are glucose insensitive. Current-clamp recordings were made using the perforated patch technique from POMC $\alpha 2 \mathrm{KO}(\mathbf{A}, \mathbf{B}$, and $\mathbf{D})$ and control (C) POMC ARC neurons. Ten nanomolar leptin (A) and $20 \mathrm{nM}$ insulin (B) were locally applied for 1-2 minutes (where indicated), inducing depolarization and hyperpolarization, respectively. The leptin-induced depolarization and insulin-induced hyperpolarization were associated with increased and decreased action potential frequency, respectively, as shown in the expanded section and in subsequent figures (lower panels). Note that spike amplitudes are truncated in the expanded sections to demonstrate changes in $\mathrm{Vm}$. Reducing glucose from 2 to $0.1 \mathrm{mM}$ reversibly hyperpolarizes and reduces firing frequency in control POMC neurons (C) but has no effect in POMC neurons lacking the AMPK $\alpha 2$ subunit (D). The broken white line in the traces represents $0 \mathrm{mV}$.

insulin, adiponectin, and T4 were indistinguishable in $A g R P \alpha 2 K O$ and control animals (Supplemental Table 1). Glucose and insulin tolerance were also normal (Supplemental Figure 3, C and D). Nevertheless, like older Agrp global-null mice (31), AgRPa2KO mice displayed increased sensitivity to MT-II (Figure 5, G-I). Therefore, these findings demonstrate that $A g R P \alpha 2 K O$ mice display a phenotype consistent with the proposed role of AMPK $\alpha 2$ in orexigenic AgRP/NPY neurons, with reduced activity of this pathway resulting in reduced body weight.

POMC neurons lacking AMPK 2 respond normally to leptin and insulin but do not sense glucose. We next used electrophysiological analysis to identify potential alterations in neuronal responsiveness to hormones and glucose in POMC $22 \mathrm{KO}$ mice. The majority of ARC neurons express functional ATP-sensitive potassium $\left(\mathrm{K}_{\mathrm{ATP}}\right)$ channels; thus exogenous ATP and/or phosphocreatine is added to the internal electrode solution to maintain these channels in a relatively quiescent state under whole-cell recording conditions $(32,33)$. However, since ATP and phosphocreatine have also been reported to inhibit AMPK activity (34), we used the perforated patch technique to avoid disruption of the intracellular environment but permit electrical continuity. Leptin depolarizes and insulin hyperpolarizes a minority of POMC neurons $(32,35)$. In our studies, POMC $\alpha 2 \mathrm{KO}$ neurons were also depolarized $(P<0.05 ; n=8)$ by leptin $(\Delta$ membrane potential $[\Delta \mathrm{Vm}]:+6.3 \pm 1.2 \mathrm{mV} ; n=4$ of 8 ; Figure $6 \mathrm{~A})$ and hyperpolarized $(P<0.05 ; n=6)$ by insulin $(\Delta \mathrm{Vm}$ : $-5.0 \pm 1.7 \mathrm{mV} ; n=3$ of 6 ; Figure $6 \mathrm{~B}$ ). Consistent with previous reports $(32,35)$, the responses of POMC and POMC $22 \mathrm{KO}$ neurons to leptin and insulin were observed to begin within 10 minutes of hormone application and slowly stabilized to a new steady-state potential, effects that were difficult to reverse even after extensive washing ( $\geq 1$ hour). Thus, AMPK $\alpha 2$ is not required for the electrophysiological effects of leptin or insulin in POMC neurons.

Brain extracellular glucose concentrations in the fed state are approximately $2.5 \mathrm{mM}$ and range between 0.5 to $0.2 \mathrm{mM}$ under fasted or hypoglycemic conditions (36). As POMC neuronal activity is modulated by changes in external glucose (37), we therefore examined whether this component of POMC neuron function was altered. POMC neurons were reversibly hyperpolarized by $-5.1 \pm 1.4$ $\mathrm{mV}(n=7 ; P<0.05$; Figure $6 \mathrm{C})$ when the external glucose concentration was acutely ( $<15$ minutes) reduced from 2 to $0.1 \mathrm{mM}$. This hyperpolarization was associated with a reversible decrease in spike firing from $2.8 \pm 0.6 \mathrm{~Hz}$ to $0.4 \pm 0.2 \mathrm{~Hz}$ in 2 and $0.1 \mathrm{mM}$ glucose $(P<0.01)$, respectively. We observed no difference in POMC membrane potential when external glucose concentrations of 2 or $10 \mathrm{mM}$ were used (data not shown). While this glucose sensitivity differs from that previously reported for POMC neurons (37), perhaps reflecting differences in methodology, glucose responsiveness in the current study is consistent with other studies in hypothalamic neurons (38). However, in POMC $22 \mathrm{KO}$ neurons, reducing the external glucose concentration from 2 to $0.1 \mathrm{mM}$ did not affect the membrane potential ( $2 \mathrm{mM}$ glucose: $-45 \pm 1 \mathrm{mV}$ versus $0.1 \mathrm{mM}$ glucose: $-46 \pm 3 \mathrm{mV} ; n=8$; NS; Figure $6 \mathrm{D}$ ) or spike fir- 

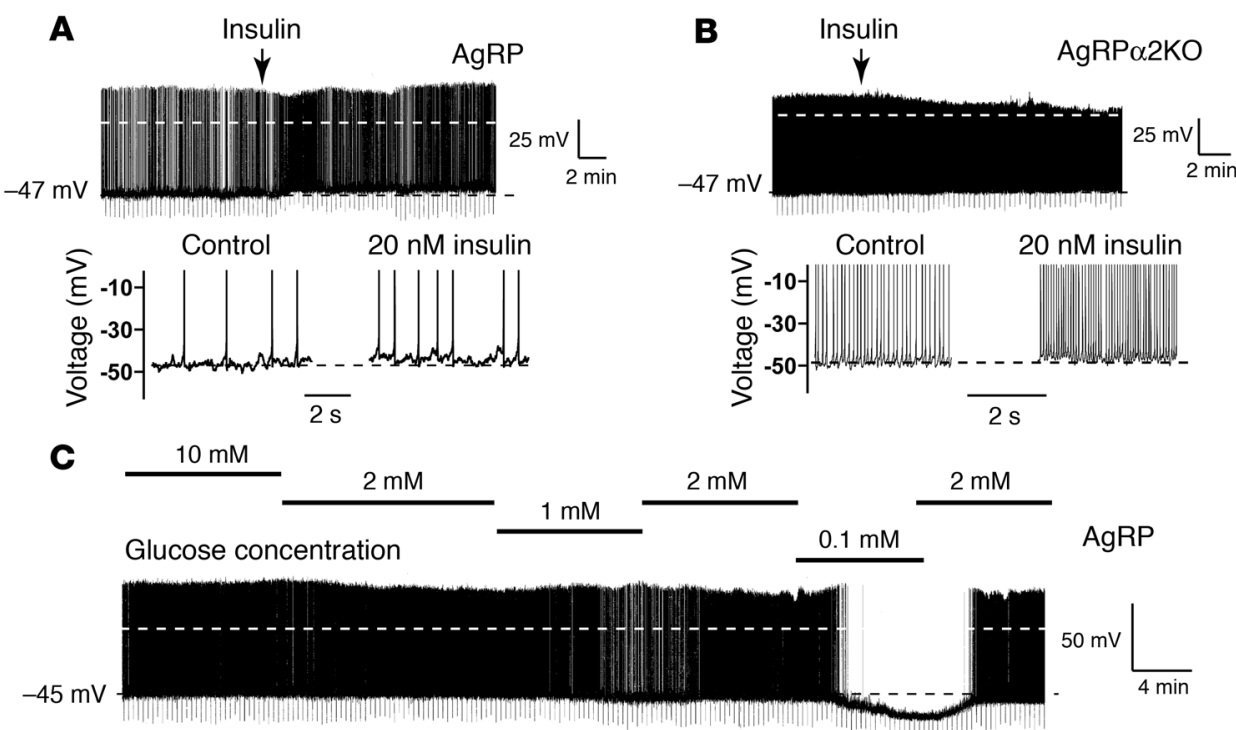

AgRP

\section{$-45 \mathrm{mV}$}

$10 \mathrm{mM}$
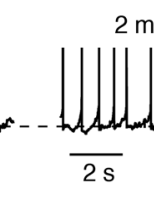

$2 \mathrm{mM}$
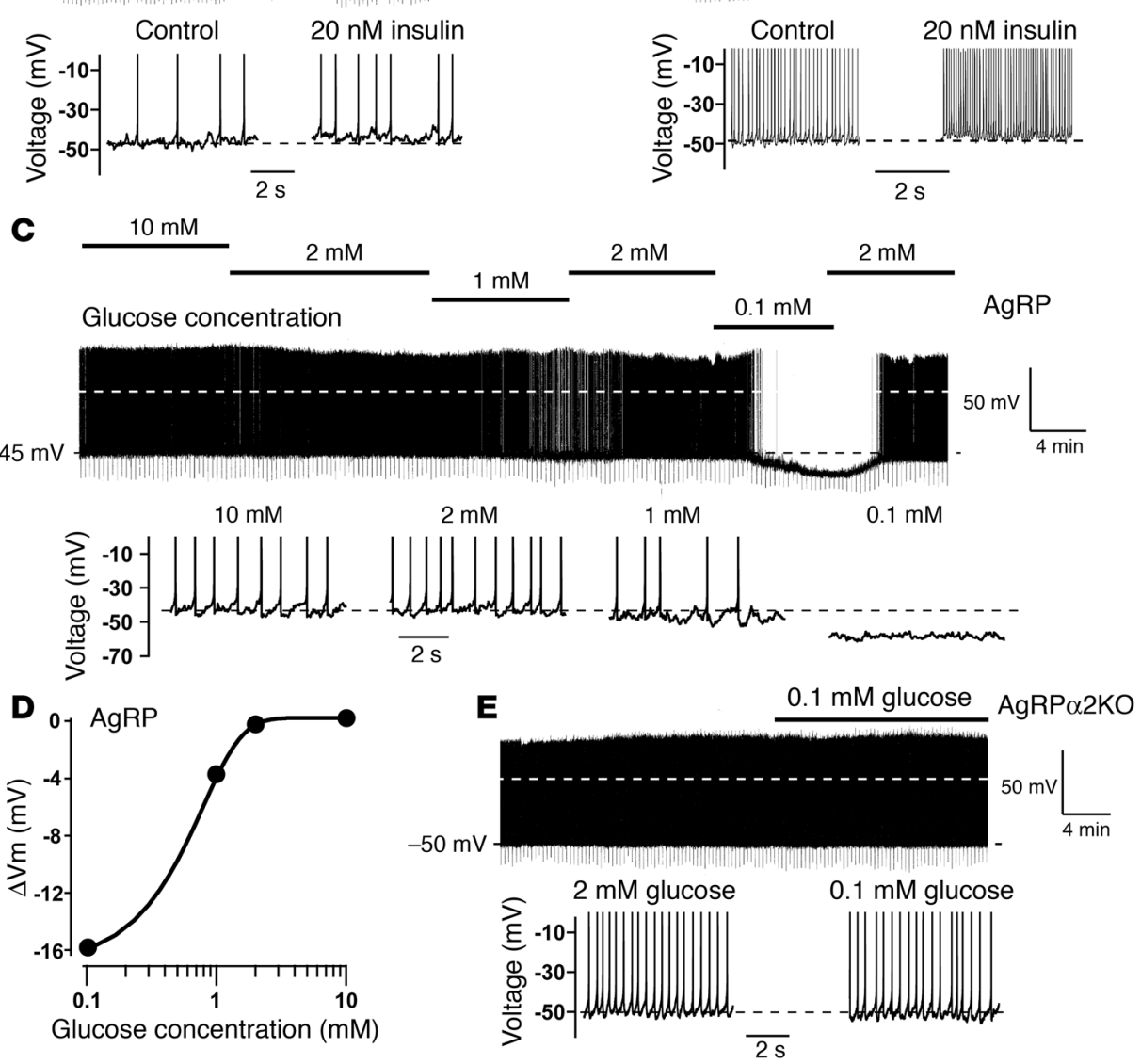

\section{Figure 7}

A minority of AgRP neurons are glucose responsive, a property absent in $A g R P \alpha 2 K O$ mice. Perforated patch, current-clamp recordings were made from control (A and $\mathbf{C}$ ) and $\mathrm{AMPK} \alpha 2 \mathrm{KO}$ (B and $\mathbf{E}$ ) AgRP ARC neurons. Control $(A)$ and AMPKa2-deleted (B) AgRP neurons were depolarized by locally applied insulin (20 nM, where indicated). (C) A minority ( $n=4$ of 14 ) of AgRP neurons respond in a concentration dependent and reversible manner to reduction (2 to $0.1 \mathrm{mM}$ ) in external glucose by membrane hyperpolarization. (D) Representative glucose dose response curve for the recording shown in C. (E) AgRP $\alpha 2 \mathrm{KO}$ neurons do not respond to reduced external glucose. The broken white line in the traces represents $0 \mathrm{mV}$. ing frequency ( $2 \mathrm{mM}$ glucose: $4.4 \pm 1.0 \mathrm{~Hz}$ versus $0.1 \mathrm{mM}$ glucose: $4.6 \pm 1.3 \mathrm{~Hz} ; n=8$; NS). These data indicate that the presence of $A M P K \alpha 2$ enables POMC neurons to sense acute changes in external glucose concentration.

A minority of $A g R P$ neurons are glucose responsive, but this property is absent in AgRP $\alpha 2 K O$ mice. Leptin hyperpolarizes Agrp/Npy-expressing pacemaker neurons in the rat ARC (39), yet under our recording conditions, leptin $(50 \mathrm{nM})$ did not alter Vm (control: $-42 \pm 1$ $\mathrm{mV}$ versus leptin: $-43 \pm 1 \mathrm{mV} ; n=11$; NS) or firing frequency (control: $2.1 \pm 0.4 \mathrm{~Hz}$ versus leptin: $2.3 \pm 0.4 \mathrm{~Hz} ; n=11$; NS) of mouse AgRP neurons. In contrast, insulin depolarized AgRP neurons $(P<0.05 ; n=8)$ by $+7.2 \pm 1.4 \mathrm{mV}(n=4$ of 8 ; Figure $7 \mathrm{~A})$ and AgRPa2KO neurons $(P<0.05 ; n=9)$ by $+3.0 \pm 0.3 \mathrm{mV}(n=5$ of 9 ; Figure $7 \mathrm{~B})$. These depolarizations were initiated within 10 minutes of insulin application and, following stabilization of response, were not easily reversed even with extensive washing ( $\geq 1$ hour). These data suggest that AMPK $\alpha 2$ is not required for the electrophysiological actions of insulin in AgRP neurons $(P>0.15)$. Our preliminary analysis suggests that insulin depolarizes AgRP neurons via a voltage-gated cation conductance (data not shown).

Rat AgRP/NPY neurons respond to an acute reduction in extracellular glucose by membrane hyperpolarization (39). In agreement with this finding, a minority of mouse AgRP neurons were reversibly hyperpolarized $(n=14 ; P=0.05)$ by $-5.2 \pm 0.6 \mathrm{mV}$ (4 of 14) when glucose was reduced from 2 to $0.1 \mathrm{mM}$ (Figure 7C). Some AgRP neurons responded to $0.1 \mathrm{mM}$ glucose with a large hyperpolarization, allowing a limited concentration response curve to be established. Reducing external glucose from 2 to 1 mM hyperpolarized AgRP neurons by approximately $20 \%$ of the response induced by $0.1 \mathrm{mM}$ glucose (Figure $7 \mathrm{D}$ ), although a hyperglycemic challenge did not affect their membrane potential (2 mM glucose: $-44 \pm 1 \mathrm{mV}$ versus $10 \mathrm{mM}$ glucose: $-43 \pm 2 \mathrm{mV}$; $n=8$; NS; Figure 7, C and D). Consistent with our observations in POMCa2KO neurons, an acute reduction in glucose (from 2 to $0.1 \mathrm{mM})$ did not affect membrane potential $(2 \mathrm{mM}$ glucose: $-51 \pm 1 \mathrm{mV}$ versus $0.1 \mathrm{mM}$ glucose: $-52 \pm 1 \mathrm{mV} ; n=18$; NS) or firing frequency ( $2 \mathrm{mM}$ glucose: $2.4 \pm 0.4 \mathrm{~Hz}$ versus $0.1 \mathrm{mM}$ glucose: $2.2 \pm 0.5 \mathrm{~Hz} ; n=18$; NS; Figure 7E) of AgRP $\alpha 2 \mathrm{KO}$ neurons. These data suggest that a minority of AgRP neurons sense physiologically relevant glucose concentrations and that this property is dependent on the presence of AMPK $\alpha 2$.

\section{Discussion}

Recent studies have shown that anorexigenic signals such as leptin, insulin, and glucose reduce AMPK $\alpha 2$ activity, while orexigenic signals, such as ghrelin and hypoglycemia, stimulate AMPK $\alpha 2$ activ- 
ity in mediobasal hypothalamic lysates $(1,12-16)$. Furthermore, virally mediated expression of activated or dominant-negative mutants of AMPK in the hypothalamus results in increased or reduced food intake, respectively $(13,15)$. Together, these studies have led to a model implicating hypothalamic AMPK as a general integrator of energy homeostasis, with this pathway playing an obligatory role in sensing nutrients and anorexigenic hormones such as leptin and insulin $(1,12)$. Given that these signals critically target ARC POMC and AgRP neurons and the ablation of both these neuronal populations profoundly affects food intake (18-20), we generated mice lacking $A M P K \alpha 2$ specifically in these cell types to examine its role in energy homeostasis.

Genetic deletion of AMPK $\alpha 2$ activity in AgRP neurons resulted in an age-related lean phenotype, consistent with the suggested role of AMPK signaling in this neuronal population. Recently, Agrpnull mice have been shown to have a similar late-onset reduction in body weight, although unlike in $A g R P \alpha 2 K O$ mice, this phenotype is associated with increased T4 levels and an elevated core body temperature (31). Furthermore, Agrp-null and AgRP 2 KO mice have enhanced MT-II sensitivity but without accompanying alterations in food intake and hypothalamic gene expression (31). The enhanced response of these animals to an exogenous melanocortin agonist may indicate reduced endogenous AgRP antagonism and/or inverse agonism at MC3/4Rs. Potential differences in other metabolic and neuroendocrine parameters may be subtle and difficult to detect in $A g R P \alpha 2 K O$ mice, as is the case in other cell-specific hypothalamic mutants, perhaps due to compensatory mechanisms in other regulatory circuits (40). Taken together, our findings suggest that the lack of AMPK $\alpha 2$ activity in AgRP neurons provides a mild anorexigenic signal, consistent with the hypothesis that this pathway acts as an energy-sensing mechanism in this cell type.

In contrast to the phenotype observed in $A g R P \alpha 2 K O$ mice, deletion of $A M P K \alpha 2$ in POMC neurons resulted in obesity. This phenotype was primarily due to reduced RMR with concomitant downregulation of BAT thermogenic genes, together with dysregulated feeding in response to a fast. POMC $22 \mathrm{KO}$ mice, however, retained sensitivity to exogenous leptin but had an imbalance in the expression of hypothalamic orexigenic and anorexigenic peptides, favoring an orexigenic output and body weight gain. These findings suggest that, at least in the case of POMC neurons, lack of AMPK activity is not associated with an anorexigenic signal.

Several explanations exist for the divergence in roles that our work assigns to the hypothalamic AMPK pathway compared with those predicted by previous studies. In our view, the most likely reason stems from differences in the experimental strategies employed in the various studies. Our constitutive deletion of $A M P K \alpha 2$ in POMC neurons could cause developmental defects in this cell type. However, after extensive analysis, we were unable to detect any anatomical, functional, or electrophysiological differences between POMC $22 \mathrm{KO}$ and wild-type POMC neurons other than the defect in glucose sensing. We also used genetic means to exclude upregulation of $A M P K \alpha 1$ as a cause of increased body weight. In contrast to our targeted approach, the literature to date is largely based upon the measurement of AMPK activity in response to exogenous hormones or nutrients in hypothalamic lysates. These preparations contain a number of different neuronal and nonneuronal cell types, all of which are likely to express AMPK, and therefore, such measurements of AMPK activity give no insights into the true activity in discrete neuronal populations. Likewise, the studies using viral transduction systems reported to date, while having the advantage of avoiding potential developmental effects, have not demonstrated which hypothalamic cell types and populations have been transduced. These caveats suggest that caution should be taken with the precise interpretation when using such nontargeted approaches. Our approach has therefore allowed us to examine the precise physiology and integrity of POMC and AgRP neurons. It is possible, however, that the phenotypes in our cell-specific gene-targeted models might arise because we are intervening in one limb of a multineuronal, highly integrated circuit and therefore physiological compensation or overcompensation may occur (40). This might result in apparently discordant phenotypes, especially as it has been suggested that hypothalamic circuits have an inherent bias toward weight gain $(40,41)$.

Nevertheless, our electrophysiological studies demonstrate that the neuromodulatory effects of leptin and insulin do not require AMPK. Indeed, most of our current knowledge of hormonal neuromodulation has been generated using whole-cell recordings, with high concentrations of exogenous ATP added to the electrode solution to prevent spontaneous $\mathrm{K}_{\mathrm{ATP}}$ channel activation. However, high ATP levels inhibit AMPK activity in in vitro biochemical assays (34), and thus many responses observed using this recording technique may well be independent of AMPK activity. Thus, our electrophysiological analysis gives further evidence that the current model identifying hypothalamic AMPK as a general integrator of hormonal and nutrient signals may not be correct.

In contrast, we reveal a key role for AMPK in glucose sensing in both POMC and AgRP neurons. Glucose levels in the hypothalamus regulate ingestive behavior through mechanisms that are thought to involve GLUT2, glucokinase, and $\mathrm{K}_{\mathrm{ATP}}$ channels (42-45). Indeed, POMC neurons express both Kir6.2 and SUR1, and glucose regulates firing rates in these cells (37). Chronic alterations in hypothalamic glucose concentration alter AMPK activity, and thus this system is well placed to sense nutrient status (46). Critically, we demonstrate that $A M P K \alpha 2$-deficient POMC and AgRP neurons fail to hyperpolarize following an acute reduction in glucose concentration, a finding that fits well with the hypothesis that AMPK acts primarily as a cellular fuel gauge (2). The molecular defects in ARC neurons underlying this loss of glucose sensing are not clear, although the lack of functional $\mathrm{K}_{\mathrm{ATP}}$ channels does

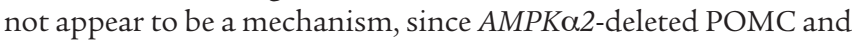
AgRP neurons spontaneously hyperpolarized during whole-cell recordings in the absence of intracellular ATP (e.g., $\mathrm{K}_{\mathrm{ATP}}$ channel activation; our unpublished observations). Moreover, since alterations in external glucose levels did not alter the excitability of all ARC POMC and AgRP neurons, these data suggest that the observed glucose responsiveness is not simply a ubiquitous neuroprotective mechanism.

One conundrum of the obesity phenotype seen in POMC $22 \mathrm{KO}$ mice is that the glucose-sensing defect in POMC neurons results in a failure to reduce neuronal firing in these neurons, which would be anticipated to lead to increased $\alpha$-MSH release and an anorexigenic output. However, a general assumption of the current literature is that tonic neuronal depolarization or hyperpolarization causes greater or lesser peptide release, respectively. While this may be true for classical neurotransmitters, peptide release is dependent on oscillatory changes in membrane potential (47). Indeed, AgRP/NPY, POMC, and other ARC neurons can convert from a tonic to a burst-firing pattern of electrical activity (ref. 39 and our unpublished observations). The complexity of the link between electrophysiological findings and physiological endpoints is fur- 
ther demonstrated by the effects of insulin on energy homeostasis. Insulin acts via the melanocortin system to reduce food intake and increase RMR (48), but its electrophysiological effects on POMC and AgRP neurons are opposite to those predicted (e.g., hyperpolarization and depolarization, respectively) $(32,35)$. Together, such observations suggest as-yet-unexplained complexity in the electrophysiological characteristics of hypothalamic neurons in relation to physiological endpoints. We suggest that under fasting conditions, POMC and a proportion of AgRP neurons may have their electrical activity significantly reduced or be quiescent. On refeeding, these neurons will respond by depolarization, with concomitant increased peptide release. Loss of this dynamic response to glucose may overall engender reduced efficacy of peptide release or may lead to desensitization in POMC target neurons. Indeed, it has been hypothesized recently that a dynamic change in AMPK activity, rather than absolute levels, is required to alter food intake (46). The consequent imbalance between orexigenic and anorexigenic signals in the hypothalamic and posthypothalamic circuitry may therefore contribute to the weight gain seen in POMC $22 \mathrm{KO}$ mice.

In conclusion, our studies reveal a critical but divergent physiological effects on energy homeostasis when $A M P K \alpha 2$ is deleted in POMC and AgRP neurons. Our observations, while demonstrating a role for AMPK in defined ARC neurons, suggest that this pathway, contrary to the prevailing view, does not act as a general integrator of energy homeostasis in the hypothalamus and show clear dissociation between the signaling mechanisms by which POMC and AgRP neurons sense glucose and those utilized by hormone signals.

\section{Methods}

Mice. The generation and genotyping of AMPKa2-flox, AMPKo1-null, POMC-Cre, and AgRP-Cre mice have been previously described (10, 20, $22,23,26)$. Mice with each floxed allele were intercrossed with the indicated Cre recombinase-expressing transgenic mice to generate compound heterozygous mice. Double heterozygous mice were intercrossed with lox ${ }^{+/-}$ mice to obtain WT, flox ${ }^{+/+}, \mathrm{Cre}$, and Creflox ${ }^{+/+}$mice for each line. To generate mice lacking floxed alleles but expressing GFP or yellow fluorescent protein (YFP) in cells harboring the deletion event, mice were intercrossed with Z/EG (49) or Rosa26YFP (50) indicator mice and bred to homozygosity for the floxed allele. Mice were maintained on a 12-hour light/12-hour dark cycle with free access to water and standard mouse chow (4\% fat; RM1; Special Diet Services) and housed in specific pathogen-free barrier facilities. Mice were handled and all in vivo studies performed with approval of the Home Office (London, United Kingdom). All knockout and transgenic mice were studied with appropriate littermate controls.

Metabolic studies. Body weights were determined using a Sartorius BP610 balance. Blood samples were collected from mice via tail vein or trunk bleeds using a capillary blood collection system with Li-Heparin (Sarstedt Inc.). Blood glucose was measured using a Glucometer Elite (Bayer). Plasma insulin levels were analyzed by an ultrasensitive rat insulin ELISA (Crystal Chem Inc.) using a mouse standard or by a mouse insulin ELISA from Linco Inc. Leptin levels were determined using a mouse leptin ELISA (Crystal Chem Inc. or Linco). Corticosterone levels were measured at early light phase using an OCTEIA corticosterone enzyme immunoassay (EIA) (IDS). Adiponectin levels were determined by ELISA (R\&D Systems), and T4 levels were measured using a T4 EIA (Diagnostic Systems Laboratories). Glucose tolerance tests were performed on mice after a 16-hour overnight fast. Animals were injected i.p. with D-glucose $(1.5 \mathrm{~g} / \mathrm{kg})$ and blood glucose levels determined by a glucometer at the indicated time points. Insulin tolerance tests were performed on randomly fed animals at 1400 hours, with $0.75 \mathrm{IU} / \mathrm{kg}$ of soluble insulin injected i.p. and blood glucose levels determined as described above.
Food intake, leptin and MT-II treatment, and HFD studies. We housed mice singly and acclimatized them for at least 1 week prior to study by subjecting them to overnight fasts and sham injections prior to implementing the study protocol. Food intake and body weight were measured for 5-7 consecutive days at the ages indicated. For fasting-refeeding studies, mice were overnight fasted and refed with a preweighed amount of food. Food intake was measured at the indicated time points. For peripheral leptin treatment, mice were treated with either $1.5 \mu \mathrm{g} / \mathrm{g}$ recombinant mouse leptin (R\&D Systems) or vehicle injected i.p. 1 hour before lights-out and at 0800 hours for 3 consecutive days. Food and body weights were recorded before injection, during the treatment period, and for a 3-day washout period following the study. For MT-II treatment studies, overnight-fasted mice were injected with $50 \mu \mathrm{g}$ of MT-II (Bachem) or vehicle at 0800 hours and food intake monitored for 24 hours. For HFD studies, mice were fed with a diet containing $45 \%$ fat, $20 \%$ protein, and $35 \%$ carbohydrate (Research Diets Inc.) for the indicated number of weeks.

Measurement of metabolic rate. RMR was measured at thermoneutral temperature by open-flow respirometry in male mice using a paramagnetic oxygen analyzer (1100 series; Servomex) and an infrared carbon dioxide analyzer (1400 series; Servomex) $(35,51)$. DEE (kJ/d) was estimated using the doubly labeled water technique in the same mice (24). To partition the effects of RMR from DEE, we converted RMR $\left(\mathrm{ml} \mathrm{O}_{2} / \mathrm{min}\right)$ to its energy equivalents $(\mathrm{kJ} / \mathrm{d})$ using the relevant equations $(25,52)$. This enabled separation of the RMR component of DEE from the energy expended during the physical activity and thermoregulatory components of the energy budget (DEE minus RMR) (24, 52).

Immune complex kinase assays. AMPK activity present in immune complexes isolated by immunoprecipitation with either anti-AMPK $\alpha 1$ or antiAMPK $\alpha 2$ antibodies bound to protein G-sepharose was determined using the SAMS peptide assay (53).

Hypothalamic immunohistochemistry and in situ bybridization. Hypothalamic immunohistochemistry and in situ hybridization (ISH) were performed as previously described (35). Rabbit anti-POMC precursor antibody and rabbit anti-AgRP antibody (Phoenix Pharmaceuticals Inc.) were used to detect POMC neurons and AgRP nerve fibers, respectively. Sheep anti-AMPK $\alpha 2$ antibody (54) was used to detect AMPK 22 expression. ISH riboprobes were generated using mouse sequences (Pomc: Genbank accession number NM_008895; and Npy: NM_023456). Imaging was performed with an Olympus BX51 microscope with either a Hamamatsu 95 black-and-white camera or a Jenoptik PrgRsC14 color camera combined with SimplePCI capture and deconvolution software.

Neuron counts and area. Brains from 12- to 15-week-old control and $P O M C \alpha 2 K O$ or $A g R P \alpha 2 K O$ mice were processed (35) and cut in $25-\mu \mathrm{m}$ coronal sections on a microtome. Sections throughout the ARC (bregma -1.1 $\mathrm{mm}$ to $-2.7 \mathrm{~mm}$ ) were collected in 3 series. The distribution and number of POMC or AgRP neurons were determined in 1 series. To estimate the total cell number, we multiplied the neuron count by 3 to account for the 3 series. Average somatic area and diameter were analyzed in at least 500 POMC neurons ( $n=5-6$ mice per genotype) and $100 \mathrm{AgRP}$ neurons $(n=2-3$ mice per genotype). The area occupied by POMC and AgRP neurons was manually scored using SimplePCI software.

$m R N A$ quantification by quantitative RT-PCR analysis. Quantitative RT-PCR was performed as previously described (35). Proprietary sequence Taqman Gene Expression assay FAM/TAMRA primers (Applied Biosystems) were used: Agrp (Mm00475829_g1), Gapdh (Mm99999915_g1), hypoxanthine guanine phosphoribosyl transferase (Hprt; Mm00446968_m1), Npy (Mm00445771_m1), Pgc1 (Mm00731216_s1), Pomc (Mm00435874_m1), growth hormone (Mm01258409_g1), thyroid-stimulating hormone $\beta$ subunit (Mm00437190_m1), and Ucp1 (Mm00494069_m1).

Electrophysiology. Hypothalamic coronal slices $(350 \mu \mathrm{m})$ were cut from 8- to 16-week-old POMCCreZ/EG and AgRPCreRosa26YFP and equivalent 
AMPKo2-null mice and maintained at room temperature $\left(22-25^{\circ} \mathrm{C}\right)$ in an external solution containing (in mM) $125 \mathrm{NaCl}, 2.5 \mathrm{KCl}, 1.25 \mathrm{NaH}_{2} \mathrm{PO}_{4}$, $25 \mathrm{NaHCO}_{3}, 2 \mathrm{CaCl}_{2}, 1 \mathrm{MgCl}_{2}, 10$ D-glucose, 15 D-mannitol, equilibrated with $95 \% \mathrm{O}_{2}, 5 \% \mathrm{CO}_{2}$, pH 7.4 (35). Neurons were visualized in the ARC by video-enhanced differential interference contrast microscopy, and the expression and excitation of GFP and YFP were used to identify POMC and AgRP neurons, respectively.

Whole-cell recordings were made at approximately $33^{\circ} \mathrm{C}$ using a modified external solution containing $2 \mathrm{mM}$ glucose with concentrations of $\mathrm{CaCl}_{2}(0.5 \mathrm{mM})$ and $\mathrm{MgCl}_{2}(2.5 \mathrm{mM})$ adjusted to reduce synaptic activity. D-Mannitol was used to correct osmolarity (310-320 mOsmol) when external glucose concentrations were reduced. Current-clamp recordings were made using borosilicate glass pipettes (4-8 M $\Omega$ ) containing (in $\mathrm{mM}$ ) 130 K-gluconate, $10 \mathrm{KCl}, 0.5 \mathrm{EGTA}, 1 \mathrm{NaCl}, 0.28 \mathrm{CaCl}_{2}, 3 \mathrm{MgCl}_{2}$, and $10 \mathrm{HEPES}$ ( $\mathrm{pH} 7.2$ ). Perforated patch was achieved by the addition of 3.5 to $5 \mu \mathrm{g} / \mathrm{ml}$ of gramicidin D and $95-125 \mu \mathrm{g} / \mathrm{ml}$ of amphotericin B to the patch pipette solution. Note that antibiotic concentrations were adjusted on a daily basis, and perforation into the whole configuration required $10-40$ minutes. ATP was omitted from the electrode solution so that neurons that fully perforated into the whole-cell configuration spontaneously hyperpolarized (due to $\mathrm{K}_{\mathrm{ATP}}$ activation) and thus were rejected. Whole-cell series and input resistance was continuously monitored in current-clamp by periodic hyperpolarizing pulses (5-15 pA; 200-ms duration; 0.05 Hz). Series resistances (40-70 $\mathrm{M} \Omega$ in perforated patch and $10-30 \mathrm{M} \Omega$ in conventional whole cell) were compensated using an Axopatch 200B amplifier (Molecular Devices) in current $\left(\mathrm{I}_{\text {fast }}\right)$ and voltage-clamp modes. Miniature inhibitory and excitatory postsynaptic currents (mIPSCs and mEPSCs, respectively) were recorded in the conventional whole-cell configuration, voltage-clamped at $-70 \mathrm{mV}$, using a CsCl-based $(130 \mathrm{mM})$ internal solution containing $5 \mathrm{mM}$ lidocaine $\mathrm{N}$-ethyl bromide (QX-314) to prevent regenerative spikes (33). mIPSCs were isolated by the addition of $5 \mu \mathrm{M}$ 2,3-dihydroxy-6-nitro-7-sulfamoylbenzo[f]quinoxaline-2,3-dione (NBQX) and $50 \mu \mathrm{M}$ D-2-amino-5-phosphonopentanoic acid (D-AP5) or $2 \mathrm{mM}$ kynurenic acid to the external solution, and mEPSCs were isolated by $20 \mu \mathrm{M}(+)$-bicuculline. Whole-cell currents and voltages were filtered at 5 and $2 \mathrm{kHz}$, respectively, and stored unsampled on digital audio tape for offline analysis using Clampex 9.2 (Molecular Devices) and IGOR Pro (version 4; WaveMetrics).

Following a minimum of 10 minutes of stable recording, drugs were applied for 1-2 minutes using a broken-tipped pipette $(\sim 4 \mu \mathrm{m})$ positioned above the recording neuron (35). Stock reagents were diluted $(\geq 1,000$ fold) in a modified external solution with $\mathrm{NaHCO}_{3}$ replaced with HEPES (10 mM, pH 7.4). Stocks of recombinant leptin (R\&D Systems) were dissolved in $\mathrm{HCl}$ and $\mathrm{pH}$ maintained with $\mathrm{NaOH}$. Insulin was purchased from Novo Nordisk and diluted in the HEPES-buffered external solution. All other reagents were purchased from Sigma-Aldrich. Stocks of D-AP5 and QX-314 were dissolved in water; NBQX dissolved in methanol; (+)-bicuculline, gramicidin D, and amphotericin B dissolved in DMSO; and kynurenic acid titrated with $\mathrm{NaOH}$.

Healthy neurons were identified by $\mathrm{Vm}(<-40 \mathrm{mV})$, input resistance (>1 G $\Omega$ ), holding current (between 0 and $-20 \mathrm{pA}$ at $-70 \mathrm{mV}$ ), spike amplitudes (>0 mV), and visual morphological assessment (lack of blebbing and nucleus not visually present). Using these criteria, we observed biophysical properties that are consistent with ARC neurons in adult mice brain slices
$(32,33)$. Samples of $V m$ that were devoid of action potentials and obvious synaptic activity were measured from 2- to 5-minute stretches of data and a mean \pm SD obtained. A neuron was determined to be responsive when the change in Vm was greater than 3 times the SD (33). However, statistical significance was calculated for all recordings (responsive and nonresponsive) within a data set. Unitary events with linear rise and decay kinetics were identified using the template detection function in Clampex 9.2.

Ex vivo hypothalamic slice experiments. Hypothalamic explants studies were performed essentially as previously described (55). In brief, mice were killed by cervical dislocation, and the whole brain was removed immediately, mounted with the ventral surface uppermost, and placed in a vibrating microtome. A $2.0-\mathrm{mm}$ slice was taken from the base of the brain to include the paraventricular nucleus and the ARC and immediately transferred to artificial cerebrospinal fluid (aCSF) equilibrated with $95 \% \mathrm{O}_{2} / 5 \%$ $\mathrm{CO}_{2}$ and maintained at $37^{\circ} \mathrm{C}$. After an initial 2-hour equilibration period, the hypothalami were incubated for 45 minute in aCSF (basal period). The viability of the tissue was verified by a 45 -minute exposure to $56 \mathrm{mM}$ $\mathrm{KCl}$. At the end of each period, the aCSF was removed and frozen until being assayed for $\alpha$-MSH, AgRP, and NPY by radioimmunoassay (Phoenix Pharmaceuticals Inc.). Hypothalamic explants that failed to show peptide release in response to $\mathrm{KCl} 3$ times greater than that of the basal period were excluded from analysis.

DEXA scanning. Body fat mass and bone mineral content were determined by DEXA using a PIXImus densitometer (GE Lunar).

Statistics. Data are expressed as mean \pm SEM. $P$ values were calculated using nonparametric (Mann-Whitney $U$ test) and parametric (unpaired and paired 2-tailed Student's $t$ tests) tests, performed as appropriate. $P$ values $\leq 0.05$ were considered statistically significant.

\section{Acknowledgments}

The work was supported by grants from the Biotechnology and Biological Sciences Research Council (to D.J. Withers), the Medical Research Council (to D.J. Withers, R.L. Batterham, and D. Carling), the Wellcome Trust (to D.J. Withers and M.L.J. Ashford), the European Commission (contract LSHM-CT-2004-005272 to D. Carling and B. Viollet), the NIH (DK-48506 to G.S. Barsh), and the Stanford Bio-X Interdisciplinary Initiatives Program (to G.S. Barsh). R.L. Batterham is a Medical Research Council Clinician Scientist. We thank T. Arnett and I. Orriss for providing access and help with the DEXA scanner. We thank G. McColl and S. Taheri for help with hypothalamic dissection and S. Lingard for help with animal husbandry.

Received for publication January 16, 2007, and accepted in revised form April 24, 2007.

Address correspondence to: Dominic J. Withers, Centre for Diabetes and Endocrinology, Rayne Institute, University College London, 5 University Street, London WC1E 6JJ, United Kingdom. Phone: 44-20-7679-6586; Fax: 44-20-7679-6583; E-mail: d.withers@ucl.ac.uk.

Marc Claret and Mark A. Smith contributed equally to this work.
1. Kahn, B.B., Alquier, T., Carling, D., and Hardie, D.G. 2005. AMP-activated protein kinase: ancient energy gauge provides clues to modern understanding of metabolism. Cell Metab. 1:15-25.

2. Hardie, D.G., Hawley, S.A., and Scott, J.W. 2006. AMP-activated protein kinase - development of the energy sensor concept. J. Physiol. 574:7-15.

3. Hawley, S.A., et al. 2003. Complexes between the
LKB1 tumor suppressor, STRAD $\alpha / \beta$ and $\mathrm{MO} 25 \alpha / \beta$ are upstream kinases in the AMP-activated protein kinase cascade. J. Biol. 2:28.

4. Hawley, S.A., et al. 2005. Calmodulin-dependent protein kinase kinase-beta is an alternative upstream kinase for AMP-activated protein kinase. Cell Metab. 2:9-19.

5. Woods, A., et al. 2005. Ca2+/calmodulin-depen- dent protein kinase kinase-beta acts upstream of AMP-activated protein kinase in mammalian cells. Cell Metab. 2:21-33.

6. Woods, A., et al. 2003. LKB1 is the upstream kinase in the AMP-activated protein kinase cascade. Curr. Biol. 13:2004-2008.

7. Hurley, R.L., et al. 2005. The Ca2+/calmodulin-dependent protein kinase kinases are AMP-activated protein 
kinase kinases. J. Biol. Chem. 280:29060-29066.

8. Minokoshi, Y., et al. 2002. Leptin stimulates fattyacid oxidation by activating AMP-activated protein kinase. Nature. 415:339-343.

9. Yamauchi, T., et al. 2002. Adiponectin stimulates glucose utilization and fatty-acid oxidation by activating AMP-activated protein kinase. Nat. Med. 8:1288-1295

10. Andreelli, F., et al. 2006. Liver adenosine monophosphate-activated kinase-alpha2 catalytic subunit is a key target for the control of hepatic glucose production by adiponectin and leptin but not insulin. Endocrinology. 147:2432-2441.

11. Daval, M., Foufelle, F., and Ferre, P. 2006. Functions of AMP-activated protein kinase in adipose tissue. J. Physiol. 574:55-62.

12. Ramamurthy, S., and Ronnett, G.V. 2006. Developing a head for energy sensing: AMP-activated protein kinase as a multifunctional metabolic sensor in the brain. J. Pbysiol. 574:85-93.

13. Minokoshi, Y., et al. 2004. AMP-kinase regulates food intake by responding to hormonal and nutrient signals in the hypothalamus. Nature. 428:569-574.

14. Andersson, U., et al. 2004. AMP-activated protein kinase plays a role in the control of food intake. J. Biol. Chem. 279:12005-12008.

15. Kim, M.S., et al. 2004. Anti-obesity effects of alphalipoic acid mediated by suppression of hypothalamic AMP-activated protein kinase. Nat. Med. 10:727-733

16. Kola, B., et al. 2005. Cannabinoids and ghrelin have both central and peripheral metabolic and cardiac effects via AMP-activated protein kinase. J. Biol. Chem. 280:25196-25201.

17. Lee, K., Li, B., Xi, X., Suh, Y., and Martin, R.J. 2005. Role of neuronal energy status in the regulation of adenosine $5^{\prime}$-monophosphate-activated protein kinase, orexigenic neuropeptides expression, and feeding behavior. Endocrinology. 146:3-10.

18. Luquet, S., Perez, F.A., Hnasko, T.S., and Palmiter, R.D. 2005. NPY/AgRP neurons are essential for feeding in adult mice but can be ablated in neonates. Science. 310:683-685.

19. Gropp, E., et al. 2005. Agouti-related peptideexpressing neurons are mandatory for feeding. Nat. Neurosci. 8:1289-1291.

20. Xu, A.W., et al. 2005. Effects of hypothalamic neurodegeneration on energy balance. PLoS Biol. 3:e415.

21. Viollet, B., et al. 2006. Activation of AMP-activated protein kinase in the liver: a new strategy for the management of metabolic hepatic disorders. J. Physiol. 574:41-53.

22. Jorgensen, S.B., et al. 2004. Knockout of the alpha2 but not alpha1 5'-AMP-activated protein kinase isoform abolishes 5-aminoimidazole-4-carboxamide-1-beta-4-ribofuranoside but not contraction-induced glucose uptake in skeletal muscle. J. Biol. Chem. 279:1070-1079.
23. Xu, A.W., et al. 2005. PI3K integrates the action of insulin and leptin on hypothalamic neurons. J. Clin. Invest. 115:951-958. doi:10.1172/JCI200524301.

24. Speakman, J.R. 1998. The history and theory of the doubly labeled water technique. Am. J. Clin. Nutr. 68:932S-938S

25. Speakman, J.R. 2000. The cost of living: field metabolic rates of small mammals. Adv. Ecol. Res. 30:177-297.

26. Viollet, B., et al. 2003. The AMP-activated protein kinase $\alpha 2$ catalytic subunit controls wholebody insulin sensitivity. J. Clin. Invest. 111:91-98. doi:10.1172/JCI200316567.

27. Coleman, D.L. 1978. Obese and diabetes: two mutant genes causing diabetes-obesity syndromes in mice. Diabetologia. 14:141-148.

28. Coleman, D.L. 1982. Diabetes-obesity syndromes in mice. Diabetes. 31:1-6.

29. Ahima, R.S., et al. 1996. Role of leptin in the neuroendocrine response to fasting. Nature. 382:250-252.

30. Takeda, S., et al. 2002. Leptin regulates bone formation via the sympathetic nervous system. Cell. 111:305-317.

31. Wortley, K.E., et al. 2005. Agouti-related proteindeficient mice display an age-related lean phenotype. Cell Metab. 2:421-427.

32. Plum, L., et al. 2006. Enhanced PIP3 signaling in POMC neurons causes $K_{A T P}$ channel activation and leads to diet-sensitive obesity. J. Clin. Invest. 116:1886-1901. doi:10.1172/JCI27123.

33. Smith, M.A., et al. 2007. Melanocortins and agoutirelated protein modulate the excitability of two arcuate nucleus neuron populations by alteration of resting potassium conductances. J. Physiol. 578:425-438.

34. Hardie, D.G., and Carling, D. 1997. The AMP-activated protein kinase - fuel gauge of the mammalian cell? Eur. J. Biochem. 246:259-273.

35. Choudhury, A.I., et al. 2005. The role of insulin receptor substrate 2 in hypothalamic and $\beta$ cell function. J. Clin. Invest. 115:940-950. doi:10.1172/ JCI200524445.

36. Routh, V.H. 2002. Glucose-sensing neurons: are they physiologically relevant? Physiol. Behav. 76:403-413.

37. Ibrahim, N., et al. 2003. Hypothalamic proopiomelanocortin neurons are glucose responsive and express K(ATP) channels. Endocrinology. 144:1331-1340.

38. Burdakov, D., et al. 2006. Tandem-pore $\mathrm{K}+$ channels mediate inhibition of orexin neurons by glucose. Neuron. 50:711-722.

39. van den Top, M., Lee, K., Whyment, A.D., Blanks, A.M., and Spanswick, D. 2004. Orexigen-sensitive NPY/AgRP pacemaker neurons in the hypothalamic arcuate nucleus. Nat. Neurosci. 7:493-494.

40. Morton, G.J., Cummings, D.E., Baskin, D.G., Barsh, G.S., and Schwartz, M.W. 2006. Central nervous system control of food intake and body weight.
Nature. 443:289-295.

41. Schwartz, M.W., et al. 2003. Is the energy homeostasis system inherently biased toward weight gain? Diabetes. 52:232-238.

42. Mobbs, C.V., et al. 2005. Impaired glucose signaling as a cause of obesity and the metabolic syndrome: the glucoadipostatic hypothesis. Physiol. Behav. 85:3-23.

43. Kang, L., et al. 2006. Glucokinase is a critical regulator of ventromedial hypothalamic neuronal glucosensing. Diabetes. 55:412-420.

44. Bady, I., et al. 2006. Evidence from glut2-null mice that glucose is a critical physiological regulator of feeding. Diabetes. 55:988-995.

45. Wang, R., et al. 2004. The regulation of glucoseexcited neurons in the hypothalamic arcuate nucleus by glucose and feeding-relevant peptides. Diabetes. 53:1959-1965.

46. Martin, T.L., et al. 2006. Diet-induced obesity alters AMP kinase activity in hypothalamus and skeletal muscle. J. Biol. Chem. 281:18933-18941.

47. Farhy, L.S., and Veldhuis, J.D. 2004. Putative GH pulse renewal: periventricular somatostatinergic control of an arcuate-nuclear somatostatin and GH-releasing hormone oscillator. Am. J. Physiol. Regul. Integr. Comp. Physiol. 286:R1030-R1042.

48. Benoit, S.C., et al. 2002. The catabolic action of insulin in the brain is mediated by melanocortins. J. Neurosci. 22:9048-9052.

49. Novak, A., Guo, C., Yang, W., Nagy, A., and Lobe, C.G. 2000. Z/EG, a double reporter mouse line that expresses enhanced green fluorescent protein upon Cre-mediated excision. Genesis. 28:147-155.

50. Srinivas, S., et al. 2001. Cre reporter strains produced by targeted insertion of EYFP and ECFP into the ROSA26 locus. BMC Dev. Biol. 1:4.

51. Selman, C., Korhonen, T.K., Bunger, L., Hill, W.G., and Speakman, J.R. 2001. Thermoregulatory responses of two mouse Mus musculus strains selectively bred for high and low food intake. J. Comp. Physiol. B Biochem. Syst. Environ. Physiol. 171:661-668.

52. Weir, J.B. 1949. New methods for calculating metabolic rate with special reference to protein metabolism. J. Physiol. 109:1-9.

53. Davies, S.P., Carling, D., and Hardie, D.G. 1989. Tissue distribution of the AMP-activated protein kinase, and lack of activation by cyclic-AMP-dependent protein kinase, studied using a specific and sensitive peptide assay. Eur. J. Biochem. 186:123-128.

54. Woods, A., Salt, I., Scott, J., Hardie, D.G., and Carling, D. 1996. The alpha1 and alpha2 isoforms of the AMP-activated protein kinase have similar activities in rat liver but exhibit differences in substrate specificity in vitro. FEBS Lett. 397:347-351.

55. Batterham, R.L., et al. 2002. Gut hormone PYY(336) physiologically inhibits food intake. Nature. 418:650-654. 